\title{
Chemically Roughened Solid Silver: A Simple, Robust and Broadband SERS Substrate
}

\author{
Shavini Wijesuriya ${ }^{1,2}$, Krishna Burugapalli ${ }^{1,2, *}$, Ruth Mackay ${ }^{1,2}$, \\ Godwin Chukwuebuka Ajaezi ${ }^{2}$ and Wamadeva Balachandran 1,3 \\ 1 Biomedical Engineering Theme, Institute for Environment, Health and Societies, Brunel University London, \\ Uxbridge UB8 3PH, UK; shav1988@gmail.com (S.W.); Ruth.MacKay@brunel.ac.uk (R.M.); \\ Wamadeva.Balachandran@brunel.ac.uk (W.B.) \\ 2 Department of Mechanical, Aerospace and Civil Engineering, College of Engineering, \\ Design and Physical Sciences, Brunel University London, Uxbridge UB8 3PH, UK; \\ gi14gga@my.brunel.ac.uk \\ 3 Department of Electronic and Computer Engineering, College of Engineering, Design and Physical Sciences, \\ Brunel University London, Uxbridge UB8 3PH, UK \\ * Correspondence: krishna.burugapalli@brunel.ac.uk; Tel.: +44-189-526-6926
}

Academic Editors: Sebastian Wachsmann-Hogiu and Zachary J. Smith

Received: 7 September 2016; Accepted: 14 October 2016; Published: 19 October 2016

\begin{abstract}
Surface-enhanced Raman spectroscopy (SERS) substrates manufactured using complex nano-patterning techniques have become the norm. However, their cost of manufacture makes them unaffordable to incorporate into most biosensors. The technique shown in this paper is low-cost, reliable and highly sensitive. Chemical etching of solid Ag metal was used to produce simple, yet robust SERS substrates with broadband characteristics. Etching with ammonium hydroxide $\left(\mathrm{NH}_{4} \mathrm{OH}\right)$ and nitric acid $\left(\mathrm{HNO}_{3}\right)$ helped obtain roughened Ag SERS substrates. Scanning electron microscopy (SEM) and interferometry were used to visualize and quantify surface roughness. Flattened Ag wires had inherent, but non-uniform roughness having peaks and valleys in the microscale. $\mathrm{NH}_{4} \mathrm{OH}$ treatment removed dirt and smoothened the surface, while $\mathrm{HNO}_{3}$ treatment produced a flake-like morphology with visibly more surface roughness features on Ag metal. SERS efficacy was tested using 4-methylbenzenethiol (MBT). The best SERS enhancement for $1 \mathrm{mM} \mathrm{MBT}$ was observed for Ag metal etched for $30 \mathrm{~s}$ in $\mathrm{NH}_{4} \mathrm{OH}$ followed by $10 \mathrm{~s}$ in $\mathrm{HNO}_{3}$. Further, MBT could be quantified with detection limits of $1 \mathrm{pM}$ and $100 \mu \mathrm{M}$, respectively, using $514 \mathrm{~nm}$ and $1064 \mathrm{~nm}$ Raman spectrometers. Thus, a rapid and less energy intensive method for producing solid Ag SERS substrate and its efficacy in analyte sensing was demonstrated.
\end{abstract}

Keywords: SERS substrate; chemical etching; solid silver; surface roughness; $514 \mathrm{~nm}$ and 1064 nm Raman

\section{Introduction}

Surface enhanced Raman spectroscopy (SERS) has a great potential for analytical testing due to:

- the high sensitivity and selectivity, including the possibility of single molecule detection;

- the possibility of multiplexed analysis;

- the availability of cheaper and better hand held Raman spectrometers; and

- the potential of point-of-sampling testing, including at home, in the clinician's office, and in the field involving standalone battery operated portable analytical instrumentation [1-10].

However, SERS is yet to reach routine analytical use [3]. The major bottlenecks for routine use of SERS include reliability, cost and the short shelf-life of the SERS substrates [1-5]. There have been 
several SERS substrate designs developed through three decades of research, but most substrate designs fall short of one or more of the above-mentioned bottlenecks [2-4]. SERS substrate designs broadly fall under three categories:

1 electrochemically roughened metal electrodes;

2 metal colloids; and

3 engineered metallic nano-patterns on planar surfaces [2].

Electrochemically roughened Ag electrodes were the first substrates on which the SERS phenomenon was discovered [11]. They are relatively low-cost to produce, but have poor SERS efficiency [1,2]. Metal colloids, on the other hand, are known to provide the best SERS enhancements [2]. However, their SERS activity is dependent on the aggregation of metal nanoparticles (NPs) with optimum distance between the NPs, which is difficult to reproduce consistently [3]. The third design category allows precise control of nano-patterns, thus producing SERS substrates with reproducible uniformity and SERS efficiency [1,2]. This precision engineering involves tedious methods and sophisticated instrumentation, making the production of nano-patterned SERS substrates expensive [1,2]. The need for specialist expertise and fabrication equipment in the design of SERS substrates, especially for the latter two design categories, has meant SERS substrates are unaffordable for routine use [1] As a result, there is a need for simple SERS substrates that are inexpensive and easy to produce [1].

A simple, fast, and inexpensive method for generating effective SERS substrates is the traditional wet chemical etching of a solid metal. The method involves immersion of the metal in an etching solution for a few seconds to minutes depending on the strength of the etching agent. The etching chemistry is typically an electrochemical process caused by the oxidation of the metal surface. An etching agent, an acid or a base, acts as a redox agent that corrodes the metal surface, while its diluent medium, e.g., water, removes the reactants and products, usually resulting in a clean surface [12,13]. If the etching is strong enough, rough nano-topography essential for SERS is generated on the metal surface. Pronounced SERS signals were reported for solid $\mathrm{Cu}$ and $\mathrm{Ag}$ foils etched with concentrated nitric acid [14-19].

It is now widely accepted that an intense electromagnetic field is generated by incident light on a plasmonic surface (typically of a noble metal, e.g., $\mathrm{Ag}$, $\mathrm{Au}$ or $\mathrm{Cu}$ ), which is the chief contributor to SERS enhancement, and potentially any material capable of generating the plasmonic field can generate a SERS signal [20]. In practice, $\mathrm{Ag}$ and $\mathrm{Au}$ metals are commonly used because they are stable in air (oxygen) and (pure) water [2]. Between $\mathrm{Ag}$ and $\mathrm{Au}, \mathrm{Ag}$ produces the largest SERS enhancement (better SERS efficacy), while $\mathrm{Au}$ is more stable (longer shelf-life) and has better biocompatibility. However, the actual material choice depends on several factors including the surface plasmon resonance wavelength and the surface nano-topography of the plasmonic material, the excitation wavelength, the spectroscopic properties of the molecule (analyte) to be tested, and the experimental setup [2,21-23]. In essence, to maximize the SERS efficiency, there would be a need to identify the right combination of the metal, its nano-structure, excitation wavelength and experimental setup for each test analyte [24]. However, it would be practical to have a universal SERS substrate that can provide meaningful SERS enhancement for detection and quantitation of any Raman active analyte of interest.

From a practical perspective, chemically roughened solid Ag metal could be one of the closest to a simple and universal SERS substrate. Ag is known for its broad plasmon resonant band, ranging from visible to near infra-red region and a large imaginary part of dielectric constants and, hence, Ag-based SERS substrates, in general, provide the most effective SERS surface [2]. Chemically roughened solid Ag metal has further benefits [16]:

- they are simpler, faster, and cheaper to produce than electrochemical roughening, metal colloids or nano-structure arrays;

- avoiding salts in the chemical etching solution, unlike the electrochemical roughening process, produces clean Ag surfaces; 
- there is no need for costly instrumentation for their production;

- Ag surfaces may suppress the undesired interference from florescence; and

- $\mathrm{Ag}$, being an excellent conductor of heat, provides good thermal stability to the chemically roughened solid SERS substrate, and hence, would minimize the sample decomposition due to the heat generated by the laser irradiation, especially, by the high power lasers required for longer wavelength Raman spectroscopy.

The objective for this study was to evaluate simple chemical etching methods to generate roughened solid Ag surfaces for SERS, and identify one such method that provides a reproducible surface roughening (hotspots) and better SERS sensitivity. Specifically, we evaluated the effects of chemical etching using ammonium hydroxide $\left(\mathrm{NH}_{4} \mathrm{OH}\right)$, nitric acid $\left(\mathrm{HNO}_{3}\right)$ and / or heat treatment on the roughening of flattened Ag wires. The resulting wires were characterized for their roughness using scanning electron microscope (SEM) and interferometry, surface composition using Energy-dispersive X-ray Spectroscopy (EDS), and SERS efficacy using $1 \mathrm{mM} 4$-methyl benzene thiol (MBT) as a model Raman active molecule and Raman spectrometers equipped with $514 \mathrm{~nm}$ and $1064 \mathrm{~nm}$ lasers for recording SERS spectra. The choice of the 514 and $1064 \mathrm{~nm}$ laser Raman spectrometers for SERS efficacy testing was to demonstrate the broad band characteristic of the Ag metal's surface plasmon resonance.

\section{Materials and Methods}

Silver wire, 99.99\% (Ag10T) $0.25 \mathrm{~mm}$ diameter with a Teflon coating was purchased from MedWire, Sigmund Cohn (Mount Vernon, NY, USA); $18 \mathrm{~m} \Omega$ deionised (DI) water purified using a Barnstead water purification system (Waltham, MA, USA) was used for all experiments; $\mathrm{NH}_{4} \mathrm{OH}$ solution $(35 \%), \mathrm{HNO}_{3}(\geq 69 \%)$, and 4-Methylbenzenethiol (98\%) (MBT) were purchased from Sigma-Aldrich Ltd. (Gillingham, Dorset, UK); and absolute ethanol was purchased from Fisher Scientific Ltd. (Loughborough, Leicestershire, UK).

To fabricate roughened solid Ag metal SERS substrates, $1.5 \mathrm{~cm}$ long Ag wire segments were cut and their Teflon cover removed. The wires were then manually flattened using a mechanical press. To wash off surface contaminants the flattened wires were ultra-sonicated in DI water for $30 \mathrm{~min}$ using a Branson 1510 sonicator. The surface of the flattened wires was then roughened using different chemical etching treatments: passive immersion in:

$135 \% \mathrm{NH}_{4} \mathrm{OH}$ for $30 \mathrm{~s}$;

$26 \mathrm{M} \mathrm{HNO}_{3}$ for $10 \mathrm{~s}$;

$36 \mathrm{M} \mathrm{HNO}_{3}$ for $2 \mathrm{~min}$;

$435 \% \mathrm{NH}_{4} \mathrm{OH}$ for $30 \mathrm{~s}$ followed by $6 \mathrm{M} \mathrm{HNO}_{3}$ for $10 \mathrm{~s}$; and

$535 \% \mathrm{NH}_{4} \mathrm{OH}$ for $30 \mathrm{~s}$ followed by $6 \mathrm{M} \mathrm{HNO}_{3}$ for $10 \mathrm{~s}$.

Following immersion in $\mathrm{NH}_{4} \mathrm{OH}$ or $\mathrm{HNO}_{3}$, the wires were rinsed in deionised water. The roughened $\mathrm{Ag}$ wires were then air-dried at room temperature. In addition, the effect of heat treatment, $130{ }^{\circ} \mathrm{C}$ for $1 \mathrm{~h}$, on the roughness and SERS efficacy of the different chemically roughened Ag wires was also tested.

The effect of chemical treatments \pm heat treatments on roughness and composition of the $\mathrm{Ag}$ metal surface was characterised using the Benchtop JCM-6000 NeoScope SEM equipped with EDS (JEOL, Welwyn Garden City, Hatfield, UK). Interferometry (Zygo New View 5000 (AMETEK Germany $\mathrm{GmbH}$, Weiterstadt, Germany) equipped with MetroPro software) was also used to visualise and quantify the surface roughness on the different Ag substrates. The roughness parameters quantified using Zygo interferometer include $\mathrm{R}_{\mathrm{a}}$ (arithmetic mean roughness), $\mathrm{R}_{\mathrm{t}}$ (sum of the maximum peak height and maximum valley depth), $R_{p}$ (maximum peak height), $R_{v}$ (maximum valley depth) and $R_{q}$ (root mean square roughness) of the surface area used for measurements [25].

Raman spectra for the different Ag substrates were recorded using two different Raman spectrometers. First was a benchtop Renishaw InVia confocal Raman microscope (Wotton-under-Edge, 
Gloucestershire, UK) equipped with $514 \mathrm{~nm}$ laser having maximum power output of $50 \mathrm{~mW}$. The samples were scanned with a $20 \times 0.4$ NA objective, $12.68 \mu \mathrm{m}$ laser spot size, $10 \%$ power, $10 \mathrm{~s}$ acquisition time, $4 \mathrm{~cm}^{-1}$ resolution and spectra recorded using Wires 3.3 software. Second was a portable StellarNet Inc. (Tampa, FL, USA) $1064 \mathrm{~nm}$ Raman spectrometer with diode laser having maximum power output of $499 \mathrm{~mW}$. The samples were scanned using a fibre optic probe at a working distance of $7.5 \mathrm{~mm}, 158 \mu \mathrm{m}$ laser spot size, $\sim 250 \mathrm{~mW}$ laser power, $5000 \mathrm{~ms}$ acquisition time, $8 \mathrm{~cm}^{-1}$ resolution and spectra recorded using SpectraWiz software. Cubic spline interpolation tool on Wires 3.3 software was used for the baseline corrections of the spectra recorded using both $514 \mathrm{~nm}$ and $1064 \mathrm{~nm}$ Raman spectrometers.

To determine their SERS efficacy, the different test Ag substrates were immersed in $1 \mathrm{mM}$ MBT solution in ethanol for $24 \mathrm{~h}$. The substrates were then rinsed three times in ethanol and air dried before scanning for Raman spectra. Solid MBT was also scanned for control Raman spectrum. The substrate that showed the best SERS enhancement namely Ag substrate etched for $30 \mathrm{~s}$ in $\mathrm{NH}_{4} \mathrm{OH}$ followed by $10 \mathrm{~s}$ in $\mathrm{HNO}_{3}$ was then further tested for efficacy in quantitation of MBT.

Statistical differences between groups $(p<0.05)$ were determined by one-way analysis of variance (ANOVA) using SPSS v20. Tukey's significant difference test was used for post hoc evaluation.

\section{Results and Discussion}

Betz et al. [1] identified four characteristics for fabrication of simple SERS substrate:

1 fabricated using equipment and reagents commonly found in chemistry laboratories;

2 minimal training or experience required for fabrication;

3 easily transported to or fabricated at the point of sampling; and

4 easily integrated into analytical systems.

The passive chemical etching method shown in this study is the closest to a simple SERS substrate. It uses common and inexpensive laboratory chemicals- $\mathrm{NH}_{4} \mathrm{OH}$ and $\mathrm{HNO}_{3}-$ for generation of simple SERS substrate on solid Ag metal surface. The chemical roughening process involves simple passive immersion in $\mathrm{NH}_{4} \mathrm{OH}$ and $\mathrm{HNO}_{3}$ for a few seconds, which would require minimal training or experience. An added advantage for this method is the possibility of regeneration of the Ag metal surface by further passive chemical etching treatment(s). The substrate can potentially be fabricated at the point of sampling in a matter of minutes. It can also be easily integrated on a point-of-care device and scanned for SERS spectrum using a portable Raman spectrometer at the point of sampling. Furthermore, to our knowledge, the synergistic effect of $\mathrm{NH}_{4} \mathrm{OH}$ and $\mathrm{HNO}_{3}$ in the generation of roughened Ag metal based SERS substrate has not been reported earlier.

Nitric acid etching has been shown to produce roughened solid metal surfaces for SERS [14-19]. Miller et al. used $2 \mathrm{~mole} / \mathrm{dm}^{3} \mathrm{HNO}_{3}$ or a combination of sandblasting and etching to obtain surface roughness features on the 10-100 nm scale on $\mathrm{Cu}$ surface [14]. These substrates were shown to provide SERS enhancements of the order of $10^{3}$ to $10^{4}$ and $10^{5}$ to $10^{6}$, respectively, for Nile Blue and p-nitrobenzoic acid using a $662 \mathrm{~nm}$ laser Raman spectrometer [14]. Xue and Dong showed the efficacy of $\mathrm{HNO}_{3}$ etching in generating simple roughened $\mathrm{Ag}$ metal SERS substrates [16]. Unlike for $\mathrm{Cu}$ surface, Xue and Dong reported that a higher concentration of $\mathrm{HNO}_{3}$ is needed for roughening of Ag surface. They immersed and vigorously stirred $\mathrm{Ag}$ foils for 2-3 $\mathrm{min}$ in $3.5 \mathrm{M} \mathrm{HNO}_{3}$ at ambient temperature to create a sponge-type surface with abundant roughness features on a 10-100 nm scale [16]. Xue and Dong reported this SERS substrate to provide stable SERS enhancements in various solvent media and elevated temperatures making them useful in studies of adsorption, molecular orientation, surface reaction, and surface catalysis at room or elevated temperatures [16]. Laserna et al. also reiterate that nitric acid etched Ag metal exhibits a strong SERS effect and excellent stability, reversibility and spectral response [17-19].

In our lab, we routinely use etching of $\mathrm{Ag}$ wires with $30 \mathrm{~s} 35 \% \mathrm{NH}_{4} \mathrm{OH}$ followed by $10 \mathrm{~s}$ in $6 \mathrm{M} \mathrm{HNO}_{3}$ to obtain a rough surface (increased surface area) for making $\mathrm{Ag} / \mathrm{AgCl}$ electrode for 
electrochemical sensing [26-28]. In this study, we investigated the efficacy of $\mathrm{NH}_{4} \mathrm{OH}$ and $\mathrm{HNO}_{3}$ in the chemical etching of the Ag metal for generating roughened solid Ag SERS substrates. $\mathrm{NH}_{4} \mathrm{OH}$ is a weak base that is commonly used for household cleaning and polishing of jewellery, wherein, it is typically used at concentrations of 5\% to $10 \%$. This generally lifts off any dirt and grime from the surface. However, when used at higher concentrations and longer immersion durations for cleaning silver metal, aqueous $\mathrm{NH}_{4} \mathrm{OH}$ is known to cause surface etching. For SERS, roughness features of 10 to $100 \mathrm{~nm}$ and their optimum spacing on a surface is desired [14-19]. Therefore, the use of the weak base $\mathrm{NH}_{4} \mathrm{OH}$ at a higher concentration (35\%), we envisioned would produce a roughened surface on the flattened $\mathrm{Ag}$ wire. On the other hand, $\mathrm{HNO}_{3}$ is a strong acid that aggressively dissolves $\mathrm{Ag}$ metal that could generate rough surface with lesser time of treatment. Thus, depending on the nature of etching solution and the length of the etching process, the roughness generated on the metal surface varies.

To identify an optimum treatment, we investigated five different treatment regimens: (1) $30 \mathrm{~s}$ $\mathrm{NH}_{4} \mathrm{OH}$; (2) $10 \mathrm{~s} \mathrm{HNO}_{3}$; (3) $2 \mathrm{~m} \mathrm{HNO}_{3}$; (4) $30 \mathrm{~s} \mathrm{NH} 4 \mathrm{OH}$ followed by $10 \mathrm{~s} \mathrm{HNO}_{3}$; and (5) $30 \mathrm{~s}$ $\mathrm{NH}_{4} \mathrm{OH}$ followed by $2 \mathrm{~m} \mathrm{HNO}_{3}$. To our knowledge, the use of $\mathrm{NH}_{4} \mathrm{OH}$ on its own for the generation of roughened $\mathrm{Ag}$ metal as SERS substrate has not been reported earlier. However, $\mathrm{NH}_{4} \mathrm{OH}$ in combination with $\mathrm{H}_{2} \mathrm{O}_{2}$ was reported by the group of Innocenti, and by Goh et al. [29-31] It is remarkable to see similar morphology on $\mathrm{Ag}$ metal surface treated with $\mathrm{NH}_{4} \mathrm{OH}+\mathrm{H}_{2} \mathrm{O}_{2}$ as reported by Innocenti et al. [29] to that we saw in our study with $\mathrm{NH}_{4} \mathrm{OH}$ treatment on its own (Figure 1b). As discussed in the following sections, $\mathrm{NH}_{4} \mathrm{OH}$ being a weak base showed slow etching (even with high concentration (35\%)) lifting off a uniform and thin layer of Ag from the surface of the Ag metal, resulting in surface roughness features more or less similar to non-treated original Ag metal surface. Hence, for this study we limited the treatment with $\mathrm{NH}_{4} \mathrm{OH}$ on its own to just one concentration. On the other hand, $\mathrm{HNO}_{3}$ is a strong acid that rapidly etches and dissolves $\mathrm{Ag}$ metal, and as discussed in the following sections, $\mathrm{HNO}_{3}$ did produce the rough surface desirable for a SERS substrate on $\mathrm{Ag}$ metal. We limited the $\mathrm{HNO}_{3}$ treatments to two time points $10 \mathrm{~s}$ and $2 \mathrm{~m}$, since the longer we immerse in $\mathrm{HNO}_{3}$, the more Ag dissolves and gets wasted. This is detrimental to the idea of a simple SERS substrate. Furthermore, we were pleasantly surprised to find the best SERS performance with $30 \mathrm{~s}$ $\mathrm{NH}_{4} \mathrm{OH}$ followed by $10 \mathrm{~s} \mathrm{HNO}_{3}$ treatment, thus minimizing the wastage of $\mathrm{Ag}$ metal in this optimised SERS substrate fabrication method. However, the effect of longer and more vigorous $\mathrm{HNO}_{3}$ treatments on SERS efficacy of roughened Ag metal was reported by Perez et al. [19]. They tested 1 to $5 \mathrm{~m}$ vigorous stirring of $\mathrm{Ag}$ foils in $6 \mathrm{M} \mathrm{HNO}_{3}$, and noted that the SERS efficacy decreases with increasing etching time, and can result in complete dissolution of the Ag foil. Our report here provides further insight (based on the interferometry results) that it is not only the spacing between neighbouring surface roughness features (generated by $\mathrm{HNO}_{3}$ treatment), but also their height that effect the SERS performance of the roughened silver metal SERS substrates. Moreover, the synergistic etching with $\mathrm{NH}_{4} \mathrm{OH}$ followed by $\mathrm{HNO}_{3}$ that we report here speeds up the etching, without the need for vigorous stirring in the method reported by Xue and Dong, and Laserna et al. [14-19]. Thus, our method avoids the need for any energy intensive instrumentation for the fabrication of the Ag metal SERS substrate.

\subsection{Morphology of Roughened Ag Substrates as Visualised Under SEM}

The $99.99 \%$ pure Ag wire of $0.25 \mathrm{~mm}$ diameter was used as the solid Ag metal for this study. The wire was flattened using a mechanical press to obtain a flat surface for Raman spectroscopy. The flattening process using a mechanical press introduced some debris (dark spots) on the Ag wire surface (Figure 1a). However, when this wire was treated with $35 \% \mathrm{NH}_{4} \mathrm{OH}$ for $30 \mathrm{~s}$, its surface changed into a bright, shiny and reflective silver colour to the naked eye. Under SEM, the $\mathrm{NH}_{4} \mathrm{OH}$ treated wire appeared clean and had a smoother surface (Figure $1 \mathrm{~b}$ ) compared to the original flattened $\mathrm{Ag}$ wire (Figure 1a). The surface of the $10 \mathrm{~s} \mathrm{HNO}_{3}$ treated $\mathrm{Ag}$ wire appeared flaky, with narrow gaps in between the flaky structures that are numerous compared to the rough features observed on the native as well as the $\mathrm{NH}_{4} \mathrm{OH}$ treated $\mathrm{Ag}$ wires (Figure 1c). On the $2 \mathrm{~m} \mathrm{HNO}_{3}$ treated surface, the flakes were worn out into smaller separated protrusions that appear like elevated peaks (Figure 1d). 


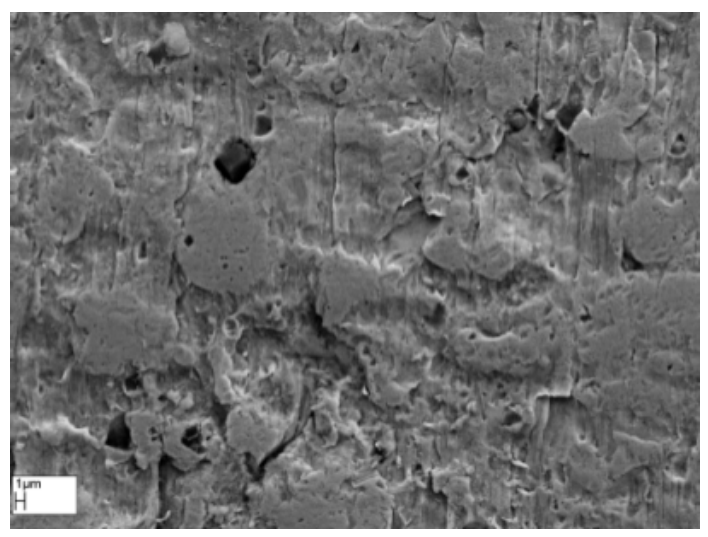

(a)

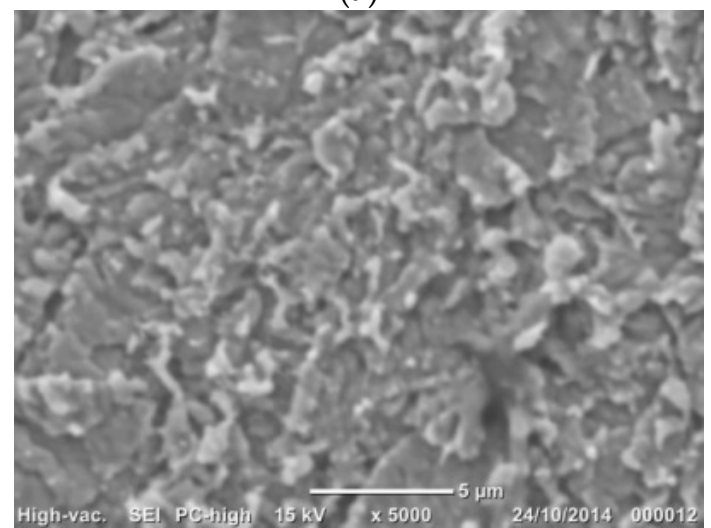

(c)

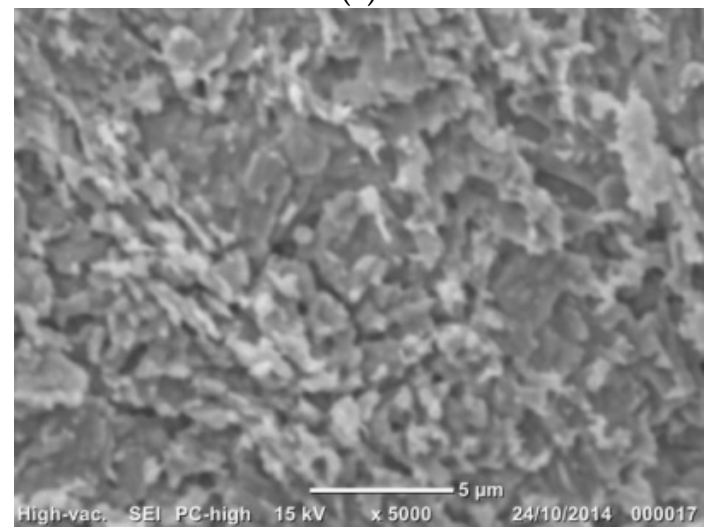

(e)

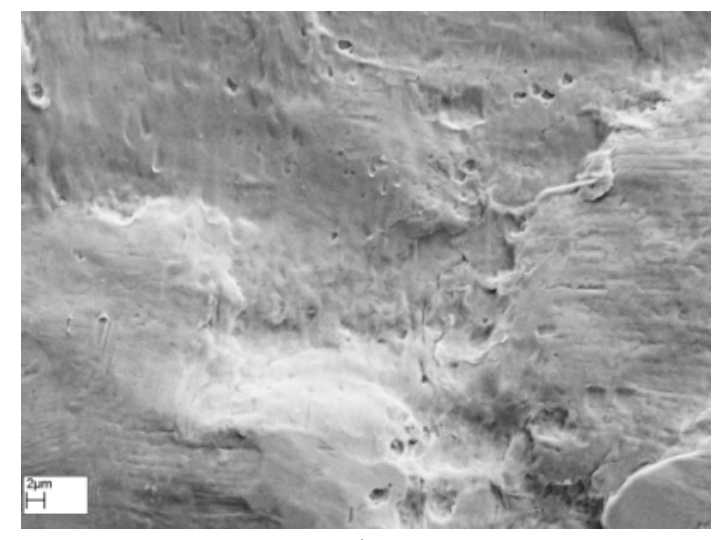

(b)

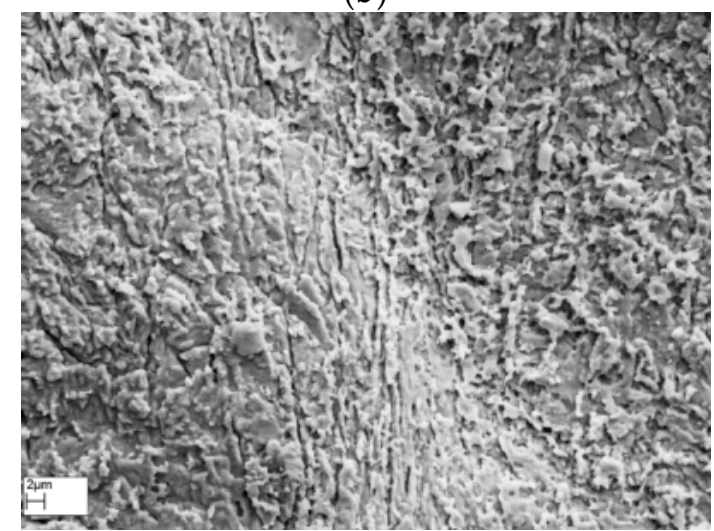

(d)

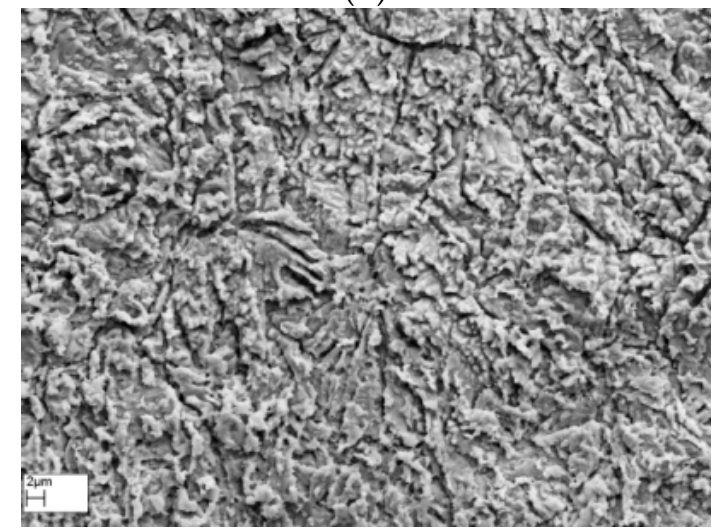

(f)

Figure 1. Effect of the different chemical etching treatments on surface morphology of Ag metal surface as seen under scanning electron microscope (SEM): (a) native as-flattened Ag wire; (b) $30 \mathrm{~s} \mathrm{NH}_{4} \mathrm{OH}$; (c) $10 \mathrm{~s} \mathrm{HNO}_{3}$; (d) $2 \mathrm{~m} \mathrm{HNO}_{3}$; (e) $30 \mathrm{~s} \mathrm{NH}_{4} \mathrm{OH}$ followed by $10 \mathrm{~s} \mathrm{HNO}_{3}$; and (f) $30 \mathrm{~s} \mathrm{NH}_{4} \mathrm{OH}$ followed by $2 \mathrm{~m} \mathrm{HNO}_{3}$.

Thereafter, we studied the synergistic effect of surface cleansing and smoothening caused by $\mathrm{NH}_{4} \mathrm{OH}$ treatment and the uniform etching caused by $\mathrm{HNO}_{3}$ treatment on the surface features and roughness on $\mathrm{Ag}$ wires. The morphology and topography of the $30 \mathrm{~s} \mathrm{NH}_{4} \mathrm{OH}+10 \mathrm{~s} \mathrm{HNO}$, and $30 \mathrm{~s}$ $\mathrm{NH}_{4} \mathrm{OH}+2 \mathrm{~m} \mathrm{HNO}_{3}$ treated $\mathrm{Ag}$ wires is shown in Figure 1e,f. The combination of $\mathrm{NH}_{4} \mathrm{OH}$ followed by $10 \mathrm{~s}$ or $2 \mathrm{~m} \mathrm{HNO}_{3}$, resulted in similar morphology to that observed with the respective $10 \mathrm{~s}$ and $2 \mathrm{~m}$ $\mathrm{HNO}_{3}$ treatments, except that the valleys between the flaky or discrete features, respectively, appeared wider and deeper. This adds variety to the surface features on the Ag wires, which could potentially provide varying degrees of SERS enhancements. 
Heat treatments were reported to affect the SERS efficacy of roughened metal surfaces [16]. Hence, we utilised heat treatment at $130{ }^{\circ} \mathrm{C}$ for $1 \mathrm{~h}$ to evaluate its physical and chemical influence on the surface properties of the native and the chemically etched Ag wires [16]. The SEM images of the heat treated native (Figure 2a), $30 \mathrm{~s} \mathrm{NH}_{4} \mathrm{OH}$ (Figure 2b), $10 \mathrm{~s} \mathrm{HNO}_{3}$ (Figure 2c), $2 \mathrm{~m} \mathrm{HNO}_{3}$ (Figure 2d), $30 \mathrm{~s} \mathrm{NH}_{4} \mathrm{OH}+10 \mathrm{~s} \mathrm{HNO}_{3}$ (Figure 2e), and $30 \mathrm{~s} \mathrm{NH} 4 \mathrm{OH}+2 \mathrm{~m} \mathrm{HNO}_{3}$ (Figure 2f) Ag substrates all showed morphology comparable to their non-heated counter parts (Figure 1a-f).

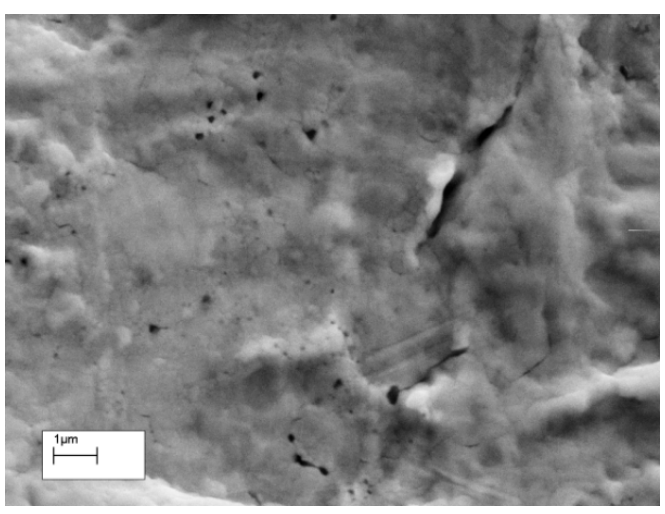

(a)

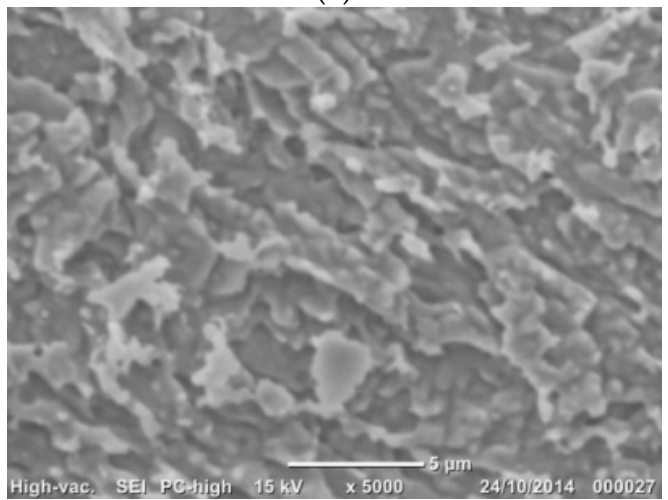

(c)

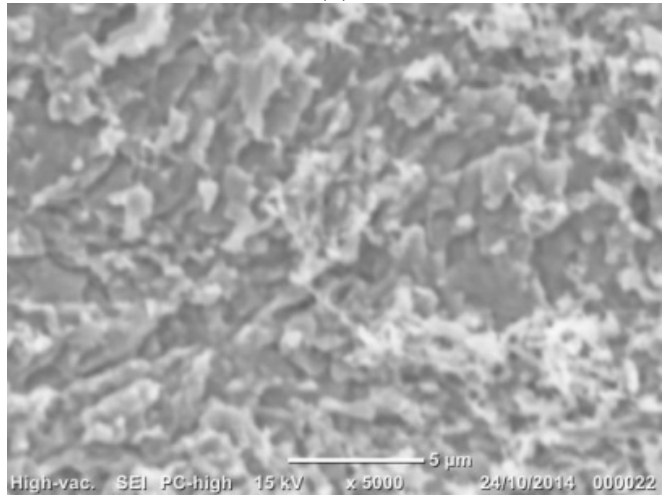

(e)

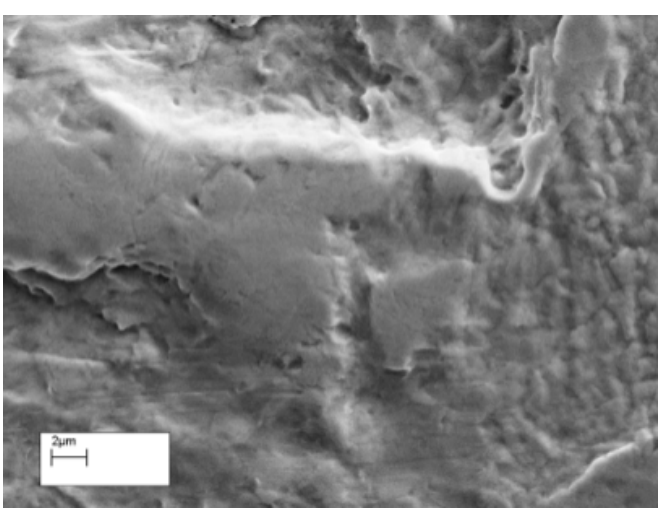

(b)

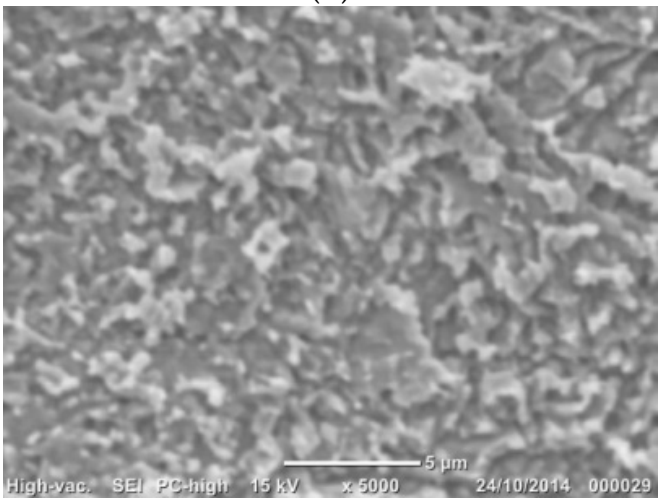

(d)

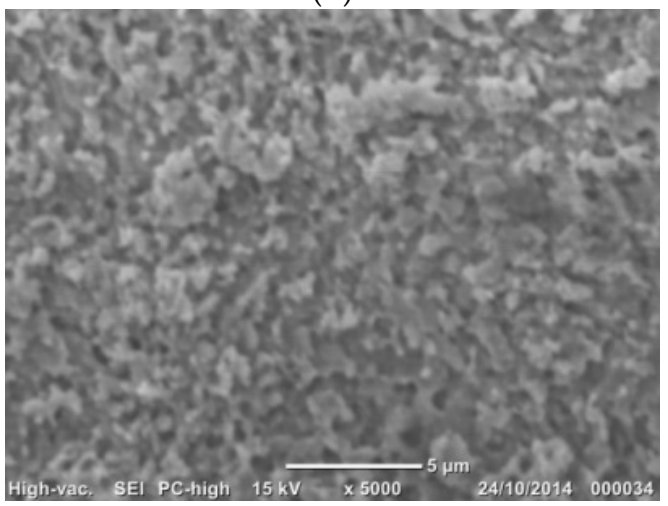

(f)

Figure 2. Effect of heat treatment, at $130{ }^{\circ} \mathrm{C}$ for $1 \mathrm{~h}$, on surface morphology of the different chemical etched Ag surfaces: (a) native flattened Ag wire washed in DI water under sonication; (b) $30 \mathrm{~s} \mathrm{NH}_{4} \mathrm{OH}$; (c) $10 \mathrm{~s} \mathrm{HNO}_{3}$; (d) $2 \mathrm{~m} \mathrm{HNO}_{3}$; (e) $30 \mathrm{~s} \mathrm{NH}_{4} \mathrm{OH}$ followed by $10 \mathrm{~s} \mathrm{HNO}_{3}$; and (f) $30 \mathrm{~s} \mathrm{NH}_{4} \mathrm{OH}$ followed by $2 \mathrm{~m} \mathrm{HNO}_{3}$.

\subsection{Topography of Roughened Ag Substrates as Mapped Using Zygo Interferometer}

The topography data presented here are the 3D surface maps recorded using Zygo New View 5000 interferometer equipped with MetroPro software. The quantitative data, namely, roughness parameters, 
associated with these 3D surface maps represent the non-periodic finer irregularities in the surface texture that provide a measure of the vertical characteristics of the surface [25]. Roughness parameters are generally abbreviated with $\mathrm{R}$ followed by letters in subscript, and are calculated on a profile (line) or on a surface (area) [25]. $R_{t}$ is the sum of the maximum peak height $\left(R_{p}\right)$ and the maximum valley depth $\left(R_{v}\right)$ as measured from the mean linear surface on the Ag wire surface. $R_{a}$ is the arithmetic mean roughness, while $R_{q}$ is root mean square roughness. The difference between $R_{a}$ and $R_{q}$ indicates the uniformity in roughness, since $\mathrm{R}_{\mathrm{q}}$ is more weighted by large values of peak height and valley depth [32]. The RMS value is typically $10 \%-25 \%$ larger than the mean value of roughness depending on the nature of the surface [32]. The surface topography profile maps and associated roughness parameter data for the different chemical etched Ag substrates are presented in Figure 3 and Table 1, respectively.

Table 1. Surface (area) roughness data for the native flattened Ag wire and the different flattened Ag wires after chemical etching treatments. ( $n=6$, mean \pm standard error of mean).

\begin{tabular}{ccccccc}
\hline & $\begin{array}{c}\mathbf{R}_{\mathbf{t}}(\mathbf{P V}) \\
(\boldsymbol{\mu \mathbf { m } )}\end{array}$ & $\mathbf{R}_{\mathbf{p}}(\boldsymbol{\mu \mathbf { m } )}$ & $\mathbf{R}_{\mathbf{v}}(\boldsymbol{\mu \mathbf { m } )}$ & $\begin{array}{c}\mathbf{R}_{\mathbf{q}}(\mathbf{R M S}) \\
(\boldsymbol{\mu \mathbf { m } )})\end{array}$ & $\mathbf{R}_{\mathbf{a}}(\boldsymbol{\mu \mathbf { m } )})$ & $\begin{array}{c}\left(\mathbf{R}_{\mathbf{q}}-\mathbf{R}_{\mathbf{a}}\right) / \mathbf{R}_{\mathbf{a}} \\
(\mathbf{\%})\end{array}$ \\
\hline $\mathrm{Native}$ & $11.15 \pm 0.89$ & $5.83 \pm 0.64$ & $5.31 \pm 0.53$ & $1.27 \pm 0.17$ & $0.95 \pm 0.10$ & 32.20 \\
$30 \mathrm{~s} \mathrm{NH}_{4} \mathrm{OH}$ & $12.04 \pm 1.15$ & $5.99 \pm 0.84$ & $6.06 \pm 0.67$ & $1.02 \pm 0.19$ & $0.77 \pm 0.15$ & 31.90 \\
$10 \mathrm{~s} \mathrm{HNO}_{3}$ & $14.63 \pm 2.09$ & $6.48 \pm 1.01$ & $8.15 \pm 1.10$ & $1.33 \pm 0.27$ & $1.03 \pm 0.21$ & 28.96 \\
$2 \mathrm{~m} \mathrm{HNO}_{3}$ & $10.04 \pm 0.59$ & $4.97 \pm 0.39$ & $5.06 \pm 0.23$ & $1.23 \pm 0.10$ & $0.96 \pm 0.09$ & 27.51 \\
$30 \mathrm{~s} \mathrm{NH}_{4} \mathrm{OH}+10 \mathrm{sNO}_{3}$ & $13.09 \pm 0.98$ & $6.05 \pm 0.58$ & $7.03 \pm 0.52$ & $1.40 \pm 0.30$ & $1.05 \pm 0.21$ & 33.52 \\
$30 \mathrm{~s} \mathrm{NH}_{4} \mathrm{OH}+2 \mathrm{~m} \mathrm{HNO}_{3}$ & $14.08 \pm 1.92$ & $5.98 \pm 0.98$ & $8.10 \pm 1.10$ & $1.95 \pm 0.41$ & $1.39 \pm 0.30$ & 40.08 \\
\hline
\end{tabular}

The surface map (Figure 3a) and the SEM image (Figure 1a) show that the flattened native Ag wires have an inherently rough topography with plateaus (green and yellow colours), troughs (blue colour indicating valleys) and irregular features (red colour indicating peaks/summits). The roughness of flattened native Ag wires was in the microscale with an $R_{t}$ value of $11.15 \pm 0.89 \mu \mathrm{m}$ and an $R_{a}$ of $0.95 \pm 0.10 \mu \mathrm{m}$. The $\mathrm{R}_{\mathrm{a}}$ lesser than 1 and the more green colour compared to yellow in the surface topography maps could indicate that the mean linear surface of the Ag wires is skewed towards the valleys (more average valleys compared to the average peaks across the surface profile) (Figure 1c and Table 1). However, a $32.20 \%$ higher $R_{q}$ value compared to its corresponding $R_{a}$ indicates that there are more high peaks and deep valleys deviating from mean linear surface of the Ag wires (Table 1) leading to an overall rougher surface.

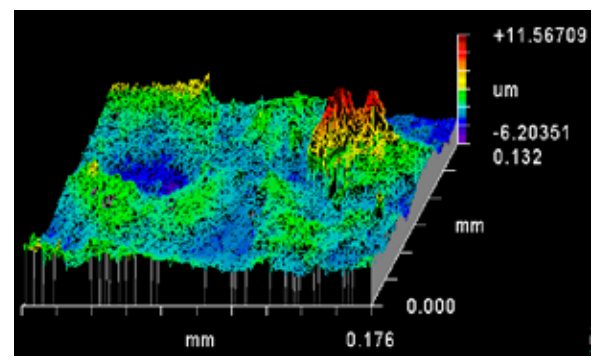

(a)

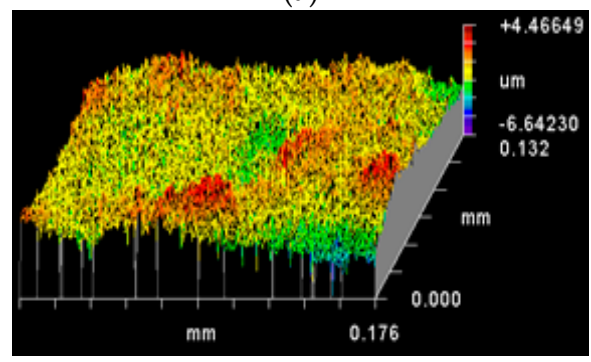

(c)

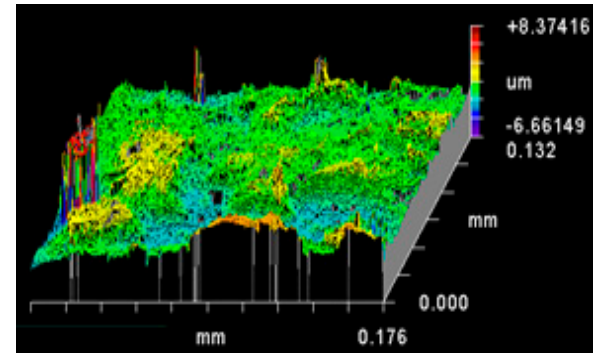

(b)

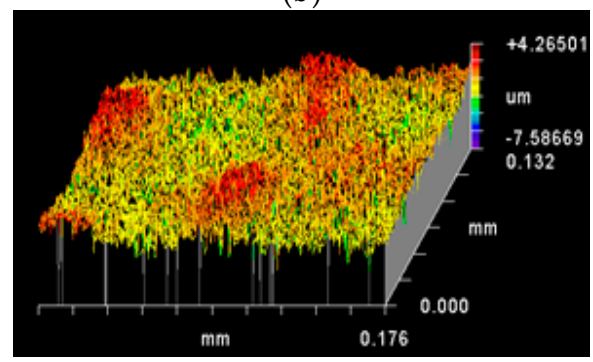

(d)

Figure 3. Cont. 


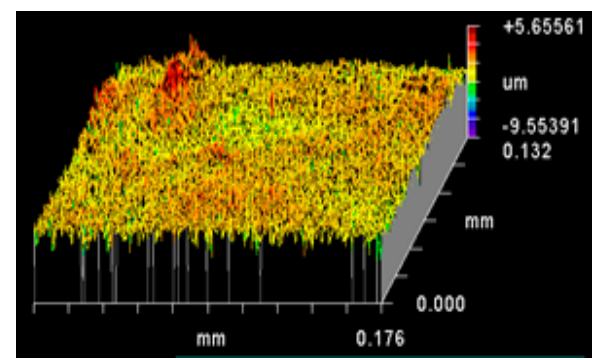

(e)

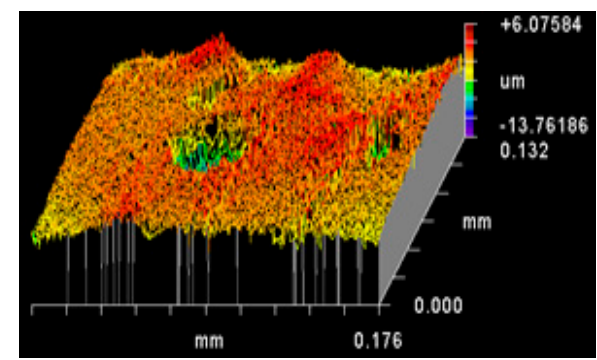

(f)

Figure 3. Effect of chemical etching treatments on surface topography (as mapped by Zygo interferometer): (a) native flattened $\mathrm{Ag}$ wire; (b) $30 \mathrm{~s} \mathrm{NH} \mathrm{NH}_{4}$; (c) $10 \mathrm{~s} \mathrm{HNO}_{3}$; (d) 2 m $\mathrm{HNO}_{3}$; (e) $30 \mathrm{~s}$ $\mathrm{NH}_{4} \mathrm{OH}$ followed by $10 \mathrm{~s} \mathrm{HNO}_{3}$; and (f) $30 \mathrm{~s} \mathrm{NH}_{4} \mathrm{OH}$ followed by $2 \mathrm{~m} \mathrm{HNO}_{3}$ etching treatments.

$\mathrm{NH}_{4} \mathrm{OH}$ has a caustic effect on Ag surface, wherein it lifts off any dirt, loose particles as well as Ag metal from the surface. In this process, $\mathrm{NH}_{4} \mathrm{OH}$ treatment not only removed any debris, but also etched a layer of $\mathrm{Ag}$ metal on the inherently rough flattened $\mathrm{Ag}$ wire surface. This etching is reflected by the decrease in roughness parameters $R_{\mathrm{q}}(1.02 \pm 0.19 \mu \mathrm{m}$ vs. $1.27 \pm 0.17 \mu \mathrm{m})$ and $R_{a}(0.77 \pm 0.15 \mu \mathrm{m}$ vs. $0.95 \pm 0.10 \mu \mathrm{m})$, without significant difference in the percentage increase in $R_{q}$ vs. $R_{a}(31.90 \%$ vs. $32.20 \%$ )) for $\mathrm{NH}_{4} \mathrm{OH}$ treated $\mathrm{Ag}$ wires compared to that for the native $\mathrm{Ag}$ wires (Table 1 and Figure $3 \mathrm{~b}$ ). However, $\mathrm{R}_{\mathrm{a}}$ was significantly lower than 1 for the $\mathrm{NH}_{4} \mathrm{OH}$ treated $\mathrm{Ag}$ wires, which could indicate that the mean linear surface is acutely skewed towards the valleys. Thus, the $\mathrm{NH}_{4} \mathrm{OH}$ treatments appear to wear the surface peaks faster than the valleys.

Unlike $\mathrm{NH}_{4} \mathrm{OH}, \mathrm{HNO}_{3}$ is a strong acid that rapidly dissolves $\mathrm{Ag}$ metal. In this study, we used $6 \mathrm{M}$ aqueous $\mathrm{HNO}_{3}$ for passive etching the surface of the flattened $\mathrm{Ag}$ wires and the etching durations were either $10 \mathrm{~s}$ or $2 \mathrm{~m}$. The quantitative topography data further reflected the differences in the surface roughness on the Ag wires induced by $\mathrm{HNO}_{3}$ treatments, when compared to that observed on the native and $\mathrm{NH}_{4} \mathrm{OH}$ treated $\mathrm{Ag}$ wire surfaces (Table 1 and Figure 3c,d). For both $10 \mathrm{~s}$ and $2 \mathrm{~m}$ $\mathrm{HNO}_{3}$ treatments, the $\mathrm{R}_{\mathrm{q}}$ and $\mathrm{R}_{\mathrm{a}}$ values were not significantly different with that observed on the native $\mathrm{Ag}$ wires. However, a lower per cent increase in $\mathrm{R}_{\mathrm{q}}$ vs. $\mathrm{R}_{\mathrm{a}}$ for both $10 \mathrm{~s}$ and $2 \mathrm{~m} \mathrm{HNO}_{3}$ treated surfaces compared to native $\mathrm{Ag}$ wire surface indicate that there are now lesser number of high peaks and deep valleys deviating from mean linear surface on the $\mathrm{HNO}_{3}$ surfaces making their roughness relatively uniform. The $\mathrm{R}_{\mathrm{a}}$ values close to 1 further indicate that there is a balance between the number of peaks and the number of valleys on the $\mathrm{HNO}_{3}$ treated $\mathrm{Ag}$ wire surfaces. Thus, the stronger $\mathrm{HNO}_{3}$ solutions appeared to cause uniform etching, when compared to $\mathrm{NH}_{4} \mathrm{OH}$ treatment that caused faster etching of peaks vs. valleys. In addition, there appear to be more surface features that are uniformly distributed on the surface, which is a desired surface for SERS signal enhancements. Between the $10 \mathrm{~s}$ and $2 \mathrm{~m} \mathrm{HNO}_{3}$ treatments, there is significant difference in the features on the surface as discussed above. It is the anisotropic shapes and separation of these surface feature, that determine the degree of SERS enhancement, and hence we have two interesting surfaces with different surface features, but similar roughness between the $10 \mathrm{~s}$ and $2 \mathrm{~m} \mathrm{HNO}_{3}$ treated $\mathrm{Ag}$ wires.

The $30 \mathrm{~s} \mathrm{NH} \mathrm{NH}_{4} \mathrm{OH}+10 \mathrm{~s} \mathrm{HNO}$ treated $\mathrm{Ag}$ wires showed an $\mathrm{R}_{\mathrm{a}}$ value of $1.05 \pm 0.21 \mu \mathrm{m}$ and per cent increase in $\mathrm{R}_{\mathrm{q}}$ vs. $\mathrm{R}_{\mathrm{a}}$ of $33.52 \%$, slightly higher than that observed with the native $\mathrm{Ag}$ wires $(0.95 \pm 0.10 \mu \mathrm{m})$, skewing the mean linear surface towards the peaks (Table 1 and Figure 3c). However, the higher $\mathrm{R}_{\mathrm{q}}(1.40 \pm 0.30 \mu \mathrm{m})$ indicates that there are more high peaks and low valleys away from the mean linear surface, which in turn is suggestive of more surface features per unit area on the $30 \mathrm{~s} \mathrm{NH} 4 \mathrm{OH}+10 \mathrm{~s} \mathrm{HNO}_{3}$ treated $\mathrm{Ag}$ wires compared to the native Ag wires (Table 1 and Figure 3c).

On the other hand, $30 \mathrm{~s} \mathrm{NH} 4 \mathrm{OH}+2 \mathrm{~m} \mathrm{HNO}_{3}$ treated $\mathrm{Ag}$ wires had significantly higher $\mathrm{R}_{\mathrm{a}}, \mathrm{R}_{\mathrm{q}}$, and per cent increase in $R_{q}$ vs. $R_{a}$, suggesting the roughest surface among all the chemical etching treatments in this study (Table 1 and Figure 3f). The reference mean linear surface is significantly 
skewed towards peaks $\left(R_{a}\right.$ of $\left.1.39 \pm 0.30 \mu \mathrm{m}\right)$. There are more number of high peaks and deep valleys away from the mean linear surface $\left(R_{\mathrm{q}}\right.$ of $\left.1.95 \pm 0.41 \mu \mathrm{m}\right)$. It also has the significantly rougher surface $\left(40.08 \%\right.$ higher $R_{q}$ vs. $R_{a}$ ) among all the chemical treatments tested in this study (Table 1 and Figure $3 f$ ).

Table 2. Surface (area) roughness data for the native flattened Ag wire and the different flattened $\mathrm{Ag}$ wires after chemical etching treatments. ( $n=6$, mean \pm standard error of mean).

\begin{tabular}{ccccccc}
\hline & $\begin{array}{c}\mathbf{R}_{\mathbf{t}}(\mathbf{P V}) \\
(\boldsymbol{\mu m})\end{array}$ & $\mathbf{R}_{\mathbf{p}}(\boldsymbol{\mu \mathbf { m } )}$ & $\mathbf{R}_{\mathbf{v}}(\boldsymbol{\mu \mathbf { m } )})$ & $\begin{array}{c}\mathbf{R}_{\mathbf{q}}(\mathbf{R M S}) \\
(\boldsymbol{\mu \mathbf { m } )})\end{array}$ & $\mathbf{R}_{\mathbf{a}}(\boldsymbol{\mu \mathbf { m } )})$ & $\begin{array}{c}\left(\mathbf{R}_{\mathbf{q}}-\mathbf{R}_{\mathbf{a}}\right) / \mathbf{R}_{\mathbf{a}} \\
(\mathbf{\%})\end{array}$ \\
\hline Native & $9.59 \pm 0.75$ & $4.39 \pm 0.25$ & $5.20 \pm 0.59$ & $1.20 \pm 0.11$ & $0.93 \pm 0.08$ & 29.18 \\
$30 \mathrm{~s} \mathrm{NH}_{4} \mathrm{OH}$ & $12.99 \pm 1.33$ & $7.12 \pm 0.59$ & $5.87 \pm 0.93$ & $1.53 \pm 0.15$ & $1.19 \pm 0.12$ & 28.62 \\
$10 \mathrm{~s} \mathrm{HNO}_{3}$ & $14.79 \pm 1.17$ & $6.88 \pm 0.97$ & $7.90 \pm 0.35$ & $1.29 \pm 0.04$ & $1.00 \pm 0.03$ & 29.75 \\
$2 \mathrm{~m} \mathrm{HNO}_{3}$ & $11.69 \pm 1.94$ & $6.02 \pm 1.33$ & $5.67 \pm 0.80$ & $1.35 \pm 0.23$ & $1.07 \pm 0.18$ & 26.30 \\
$30 \mathrm{~s} \mathrm{NH}_{4} \mathrm{OH}+10 \mathrm{~s} \mathrm{HNO}_{3}$ & $15.18 \pm 1.55$ & $7.23 \pm 0.86$ & $7.95 \pm 0.89$ & $1.58 \pm 0.19$ & $1.19 \pm 0.14$ & 32.66 \\
$30 \mathrm{~s} \mathrm{NH}_{4} \mathrm{OH}+2 \mathrm{~m} \mathrm{HNO}_{3}$ & $12.69 \pm 0.48$ & $5.67 \pm 0.40$ & $7.02 \pm 0.25$ & $1.40 \pm 0.11$ & $1.09 \pm 0.08$ & 29.11 \\
\hline
\end{tabular}

Heating at $130{ }^{\circ} \mathrm{C}$ for $30 \mathrm{~m}$ did not appear to cause significant difference in surface morphology on SEM images to naked eye (Figures 1 and 2). However, quantitative topography results showed differences in surface roughness parameters between the heated (Figure 4, Table 2) and their non-heated chemical roughened Ag substrate counterparts (Figure 3, Table 1). Ag is a soft and malleable metal, and the changes in the roughness parameter $R_{a}, R_{q}$ and per cent increase in $R_{q}$ vs. $R_{a}$ for all $A g$ surface variables, in this study, were suggestive that heating at $130{ }^{\circ} \mathrm{C}$ for $1 \mathrm{~h}$ induced restructuring of surface features on the Ag wires into less rougher surfaces compared to their respective non-heated counterparts. The per cent increase in $\mathrm{R}_{\mathrm{q}} \mathrm{vs}$. $\mathrm{R}_{\mathrm{a}}$ for the different heated $\mathrm{Ag}$ wires ranged between $26 \%$ and $33 \%$, which was lower compared to their non-heated counterparts ( $27 \%$ to $40 \%$ ). This indicates that the number of peaks higher and valleys deeper than the mean linear surface reduced. However, for $30 \mathrm{~s} \mathrm{NH} \mathrm{NH}_{4} \mathrm{OH}$ treatment, heat treatment resulted in an increased $\mathrm{R}_{\mathrm{a}}$ and $\mathrm{R}_{\mathrm{q}}$ values compared to its non-heated counterpart. This was in contrast to all of the other chemical etching treatments, where heating reduced the $\mathrm{R}_{\mathrm{a}}$ and $\mathrm{R}_{\mathrm{q}}$ values. One explanation for this could be that, the $\mathrm{NH}_{4} \mathrm{OH}$ treatment could leave amine residues on the Ag surface, since Ag metal is known to passively react with amines. $\mathrm{NH}_{4} \mathrm{OH}$ residues on a metal, when heated, are known to cause the nitriding effect, wherein the $\mathrm{NH}_{4} \mathrm{OH}$ dissociates into $\mathrm{N}_{2}$ and $\mathrm{H}_{2} \cdot \mathrm{N}_{2}$ diffuses onto the metal surface creating a nitride layer that is known to increase the mechanical properties and roughness of the surface [33].

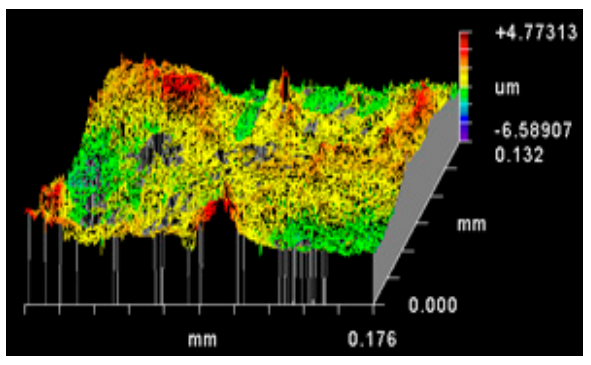

(a)

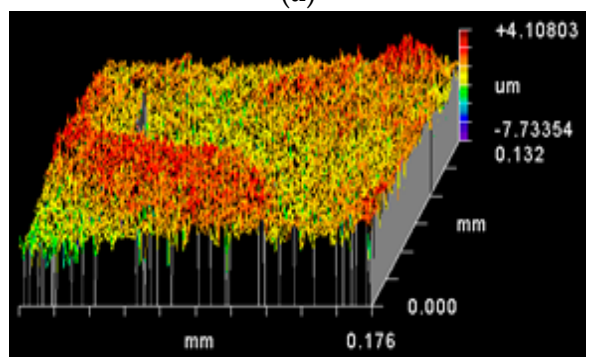

(c)

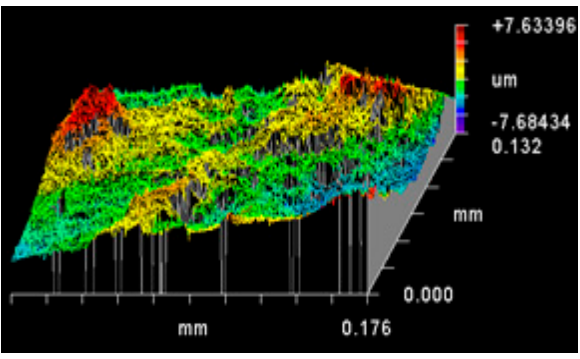

(b)

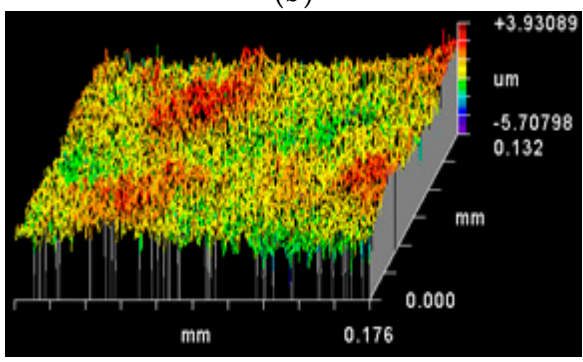

(d)

Figure 4. Cont. 


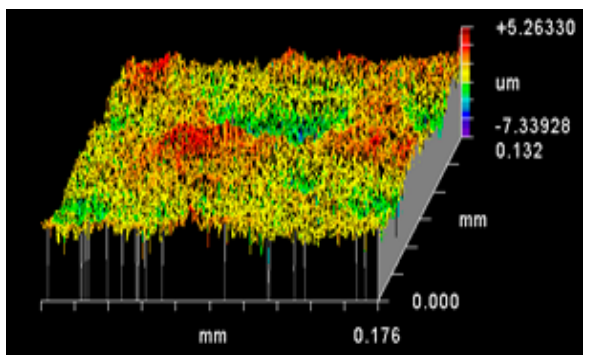

(e)

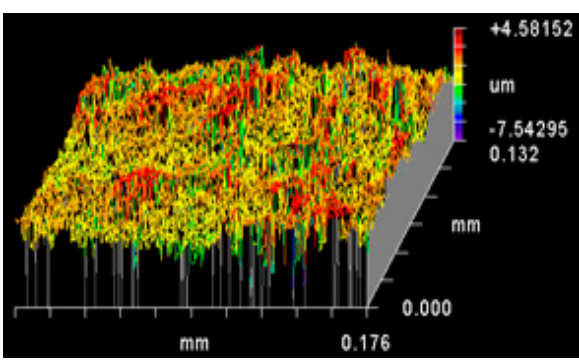

(f)

Figure 4. Effect of heat treatment at $130{ }^{\circ} \mathrm{C}$ for $1 \mathrm{~h}$ on the surface topography of the different chemical etched Ag substrates (as mapped by Zygo interferometer): (a) native flattened Ag wire; (b) $30 \mathrm{~s} \mathrm{NH}_{4} \mathrm{OH}$; (c) $10 \mathrm{~s} \mathrm{HNO}_{3}$; (d) $2 \mathrm{~m} \mathrm{HNO}_{3}$; (e) $30 \mathrm{~s} \mathrm{NH}_{4} \mathrm{OH}$ followed by $10 \mathrm{~s} \mathrm{HNO}_{3}$; and (f) $30 \mathrm{~s} \mathrm{NH}_{4} \mathrm{OH}$ followed by $2 \mathrm{~m} \mathrm{HNO}_{3}$ etching treatments.

\subsection{Surface Chemical Composition as a Function of Etching Treatments}

SERS, being a sensitive transduction mechanism, requires a clean metal surface before it is treated with an analyte of interest for detection or assay. Any contaminant on the SERS substrate surface could give unwanted SERS spectral peaks. Hence, it was important to evaluate the chemical composition, which was accomplished by recording EDS spectra. Figure 5 shows an example of the EDS spectrum as observed for the flattened $\mathrm{Ag}$ metal treated for $30 \mathrm{~s}$ with $\mathrm{NH}_{4} \mathrm{OH}$. The primary peaks observed were that of Ag (indicating high purity, >99\%). A very small peak for carbon and occasional peaks for oxygen, magnesium and aluminium were also observed, indicating the presence of residual hydrocarbons and trace amounts of metals $(\mathrm{Mg}, \mathrm{Al})$. Interestingly, irrespective of the chemical treatment performed, in this study, to etch the Ag wires as well as of the heating, all the silver surfaces tested showed EDX spectra similar to that shown in Figure 5.

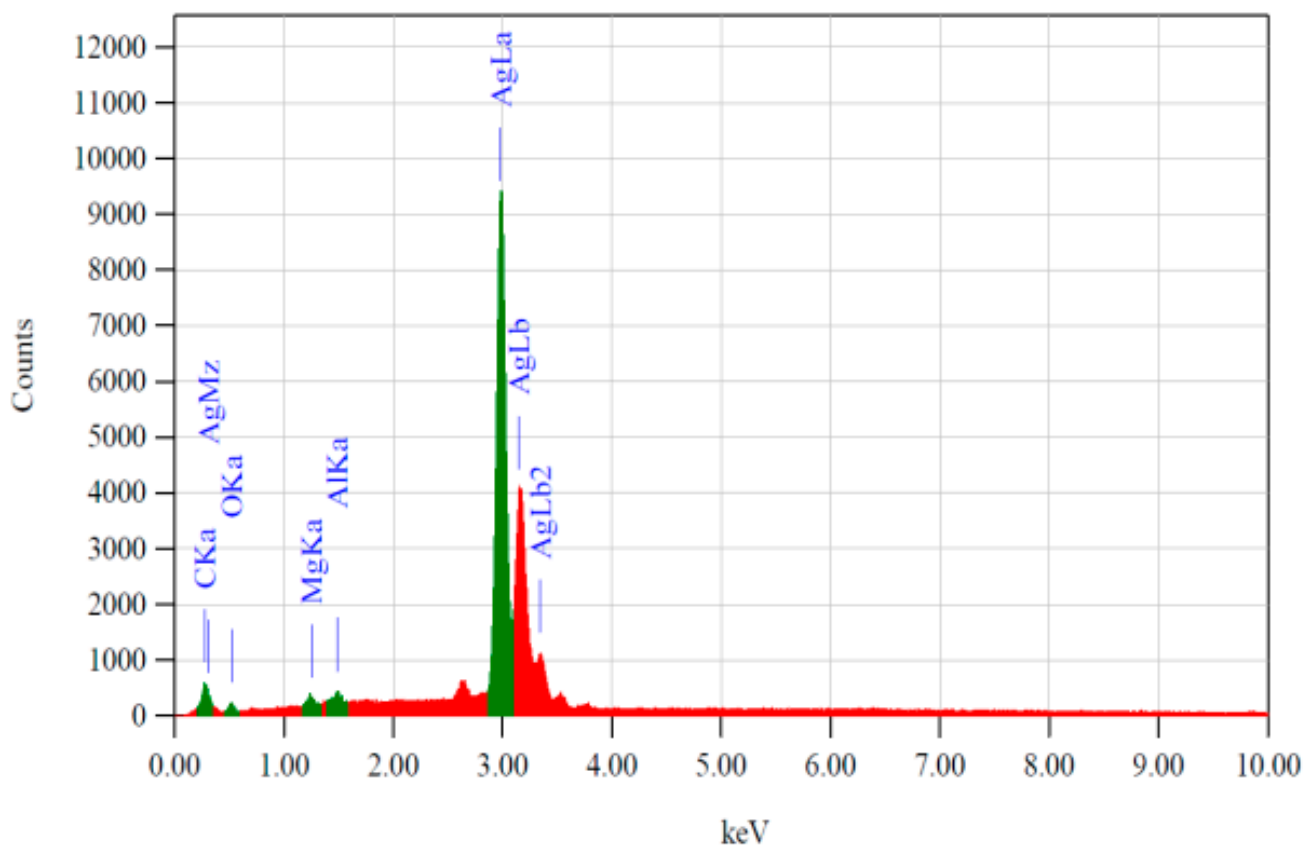

Figure 5. A typical energy-dispersive X-ray (EDS) spectrum of the flattened Ag metal predominantly showing peaks for Ag metal: AgLa, AgLb and AgLb2 lines at 2.983, 3.151 and $3.348 \mathrm{keV}$, respectively. Traces of $\mathrm{C}, \mathrm{O}, \mathrm{Mg}$ and $\mathrm{Al}$ were also seen at $0.277,0.525,1.253,1.486 \mathrm{keV}$, respectively. The spectra were similar for the different test samples in this study, irrespective of the chemical etching treatments with and without heating. 


\subsection{Efficacy of the Roughened Ag Wires in Enhancing SERS Signal}

MBT, also known as p-thiocresol, is a commonly used Raman probe molecule for SERS efficacy testing [34]. In this study, we tested the SERS efficacy of the different chemically etched Ag substrates, both heated and non-heated using MBT. The Raman spectra for solid MBT, recorded using $514 \mathrm{~nm}$ and $1064 \mathrm{~nm}$ Raman spectrometers are shown in Figure 6a. The prominent Raman peaks ( $514 \mathrm{~nm} ; 1064 \mathrm{~nm}$ ) of interest observed for bulk MBT include: S-H stretch $\left(2562 \mathrm{~cm}^{-1} ; 2573 \mathrm{~cm}^{-1}\right)$, benzene ring stretch $\left(1591 \mathrm{~cm}^{-1} ; 1592 \mathrm{~cm}^{-1}\right), \mathrm{C}-\mathrm{S}$ stretch $\left(1097 \mathrm{~cm}^{-1}\right.$ and $634 \mathrm{~cm}^{-1} ; 1085 \mathrm{~cm}^{-1}$ and $\left.609 \mathrm{~cm}^{-1}\right), \mathrm{C}-\mathrm{H}$ torsion for benzene ring $\left(794 \mathrm{~cm}^{-1} ; 781 \mathrm{~cm}^{-1}\right), \mathrm{C}-\mathrm{H}$ stretch for $\mathrm{CH}_{3}$ group $\left(2914 \mathrm{~cm}^{-1} ; 2918 \mathrm{~cm}^{-1}\right)$ and $\mathrm{C}-\mathrm{H}$ stretch for benzene ring $\left(3036 \mathrm{~cm}^{-1}\right.$ and $\left.3056 \mathrm{~cm}^{-1} ; 3059 \mathrm{~cm}^{-1}\right)$ [34-40].

For SERS efficacy testing, the Ag substrates were immersed overnight in $1 \mathrm{mM}$ MBT in ethanol. They were then washed 3 times with ethanol, to remove any non-bound MBT. For each test substrate the SERS spectra were recorded using both $514 \mathrm{~nm}$ and $1064 \mathrm{~nm}$ Raman. A comparison of the SERS spectrum of $1 \mathrm{mM}$ MBT with that of the corresponding Raman spectrum of the bulk MBT (98\%) recorded for $30 \mathrm{~s} \mathrm{NH}_{4} \mathrm{OH}+10 \mathrm{~s} \mathrm{HNO}_{3} \mathrm{Ag}$ substrate using $514 \mathrm{~nm}$ and $1064 \mathrm{~nm}$ Raman are illustrated in Figure $6 b, c$, respectively. Further, the corresponding Raman/SERS peaks are listed in Table 3.
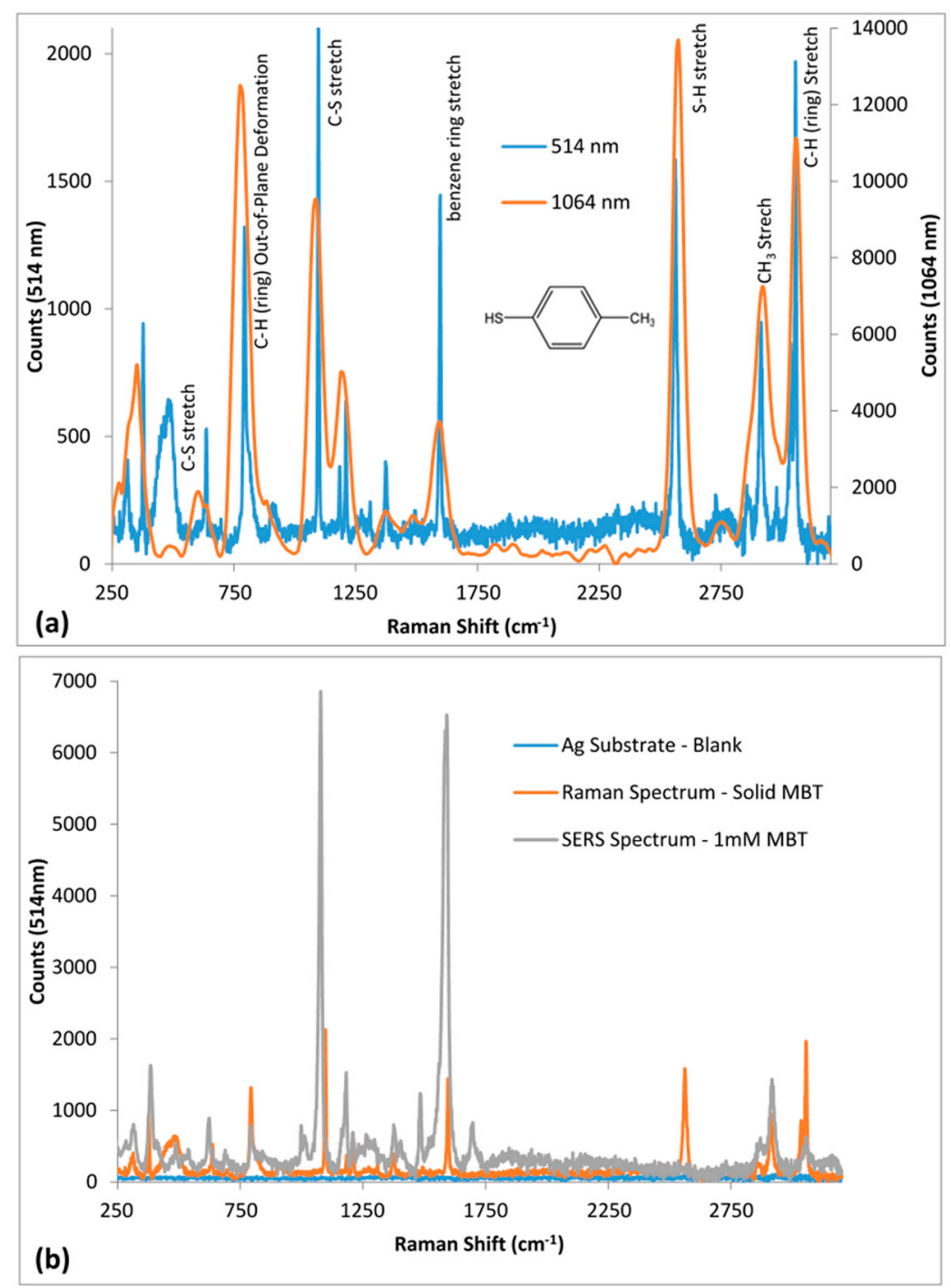

Figure 6. Cont. 


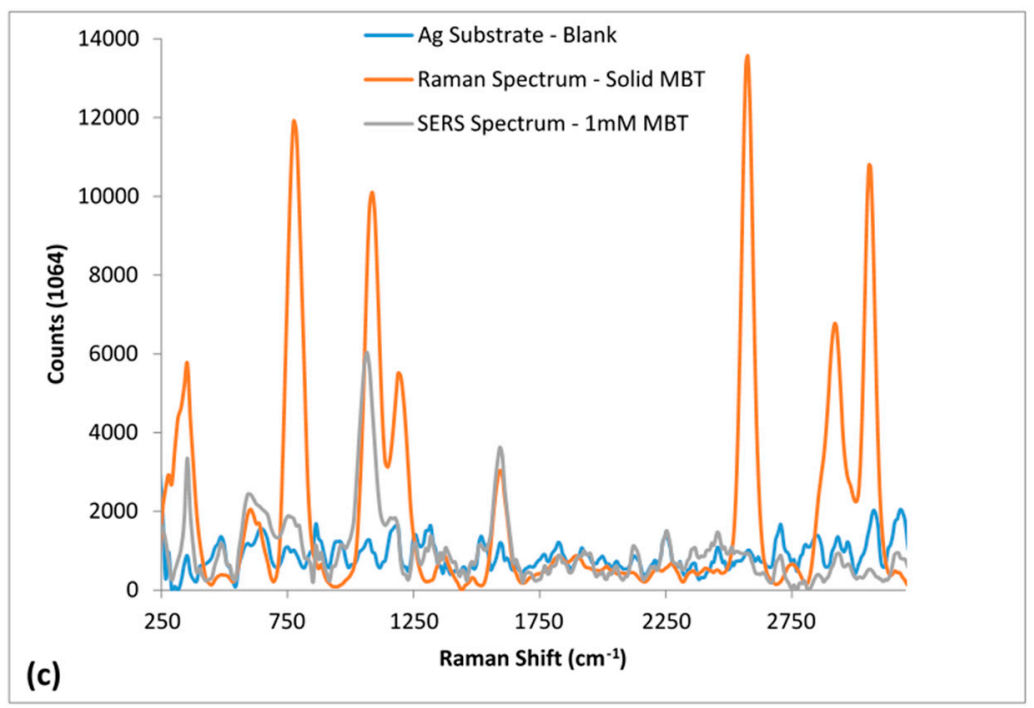

Figure 6. Raman and SERS spectra of MBT recorded using $514 \mathrm{~nm}$ and $1064 \mathrm{~nm}$ Raman spectrometers: (a) $514 \mathrm{~nm}$ and $1064 \mathrm{~nm}$ Raman spectra of solid MBT; and (b,c) $514 \mathrm{~nm}$ and $1064 \mathrm{~nm}$ SERS spectra respectively, for $1 \mathrm{mM}$ MBT on $30 \mathrm{~s} \mathrm{NH} 4 \mathrm{OH}+10 \mathrm{~s} \mathrm{HNO}_{3} \mathrm{Ag}$ substrate compared to Raman spectrum of solid MBT and the base Ag substrate (blank).

Table 3. Raman and SERS peaks $\left(\mathrm{cm}^{-1}\right)$ for MBT on spectra recorded using $514 \mathrm{~nm}$ and $1064 \mathrm{~nm}$ Raman spectrometers and the peak assignments.

\begin{tabular}{|c|c|c|c|c|}
\hline \multicolumn{2}{|c|}{514 nm Raman Peaks $\left(\mathrm{cm}^{-1}\right)$} & \multicolumn{2}{|c|}{1064 nm Raman Peaks $\left(\mathrm{cm}^{-1}\right)$} & \multirow[t]{2}{*}{ Peak Assignmen } \\
\hline Raman Spectrum & SERS Spectrum & Raman Spectrum & SERS Spectrum & \\
\hline 312 & 314 & & & $\tau_{\mathrm{r}} \mathrm{CC}[35]$ \\
\hline 377 & 388 & 347 & 353 & $\delta_{\mathrm{r}} \mathrm{CC}[34,36]$ \\
\hline 484 & & & & $\gamma_{\mathrm{r}} \mathrm{CC}[34,36]$ \\
\hline 634 & 623 & 609 & 608 & vCS [34] \\
\hline 794 & 791 & 781 & & $\tau_{\mathrm{r}} \mathrm{CH}[34]$ \\
\hline 913 & 995,1014 & & & $\gamma_{\mathrm{r}} \mathrm{CH}[34]$ \\
\hline 1097 & 1076 & 1085 & 1063 & vCS [34-38] \\
\hline 1184 & 1180 & 1198 & & $v_{\mathrm{r}} \mathrm{CC}[34]$ \\
\hline \multirow[t]{2}{*}{1209} & 1258 & & & $v_{\mathrm{r}} \mathrm{CC}[35]$ \\
\hline & & & & $v \mathrm{CH}_{3}[35]$ \\
\hline 1309,1374 & 1377 & 1372 & & $v \mathrm{CH}_{3}[34,35]$ \\
\hline 1591 & 1483,1584 & 1592 & 1592 & $v_{\mathrm{r}} \mathrm{CC}[34-38]$ \\
\hline 2562 & & 2573 & & vSH $[34,39]$ \\
\hline 2727 & & 2739 & & $\delta \mathrm{CH}_{3}[34,40]$ \\
\hline 2855,2914 & 2919 & 2918 & & $v_{\mathrm{s}} \mathrm{CH}_{3}[34,40]$ \\
\hline 2978 & & & & $v_{\mathrm{as}} \mathrm{CH}_{3}[34,40]$ \\
\hline 3036,3056 & & 3059 & & $v_{\mathrm{r}} \mathrm{CH}[34,40]$ \\
\hline
\end{tabular}

$v$ —stretching, $\delta$-in-plane bending, $\gamma$-out-of-plane bending, $\tau$-torsion, $r$-ring, $s$-symmetric, as-asymmetric.

The absence of the S-H stretch peaks at $2562 \mathrm{~cm}^{-1}$ and $2573 \mathrm{~cm}^{-1}$, respectively, in the $514 \mathrm{~nm}$ and $1064 \mathrm{~nm}$ SERS spectra shows that all MBT molecules are bound on the silver surface through Ag-S covalent bonding (Figure 7a,b). Two prominent SERS peaks reported in literature for MBT are approximately at $1075 \mathrm{~cm}^{-1}$ and $1590 \mathrm{~cm}^{-1}$ [34]. Both these peaks are prominently enhanced in both the $514 \mathrm{~nm}\left(1076 \mathrm{~cm}^{-1}\right.$ and $\left.1584 \mathrm{~cm}^{-1}\right)$ and $1064 \mathrm{~nm}\left(1063 \mathrm{~cm}^{-1}\right.$ and $\left.1592 \mathrm{~cm}^{-1}\right)$ SERS spectra, as shown in Figure 6b,c, respectively. As expected, SERS spectrum for $1 \mathrm{mM}$ MBT was strong and detailed for $514 \mathrm{~nm}$ compared to $1064 \mathrm{~nm}$. The $514 \mathrm{~nm}$ SERS spectrum for MBT showed majority of the peaks seen in the Raman spectrum for solid MBT (Table 3): 314, 388, 623, 791, 1076, 1180, 1377, 1483, 1584, 
and $2919 \mathrm{~cm}^{-1}$ on SERS spectrum corresponding to 312, 377, 637, 794, 1097, 1184, 1374, 1492, 1591 and $2914 \mathrm{~cm}^{-1}$, respectively, on Raman spectrum. The slight shift in peaks can be attributed to the changes in chemical environment of MBT on Ag surface.

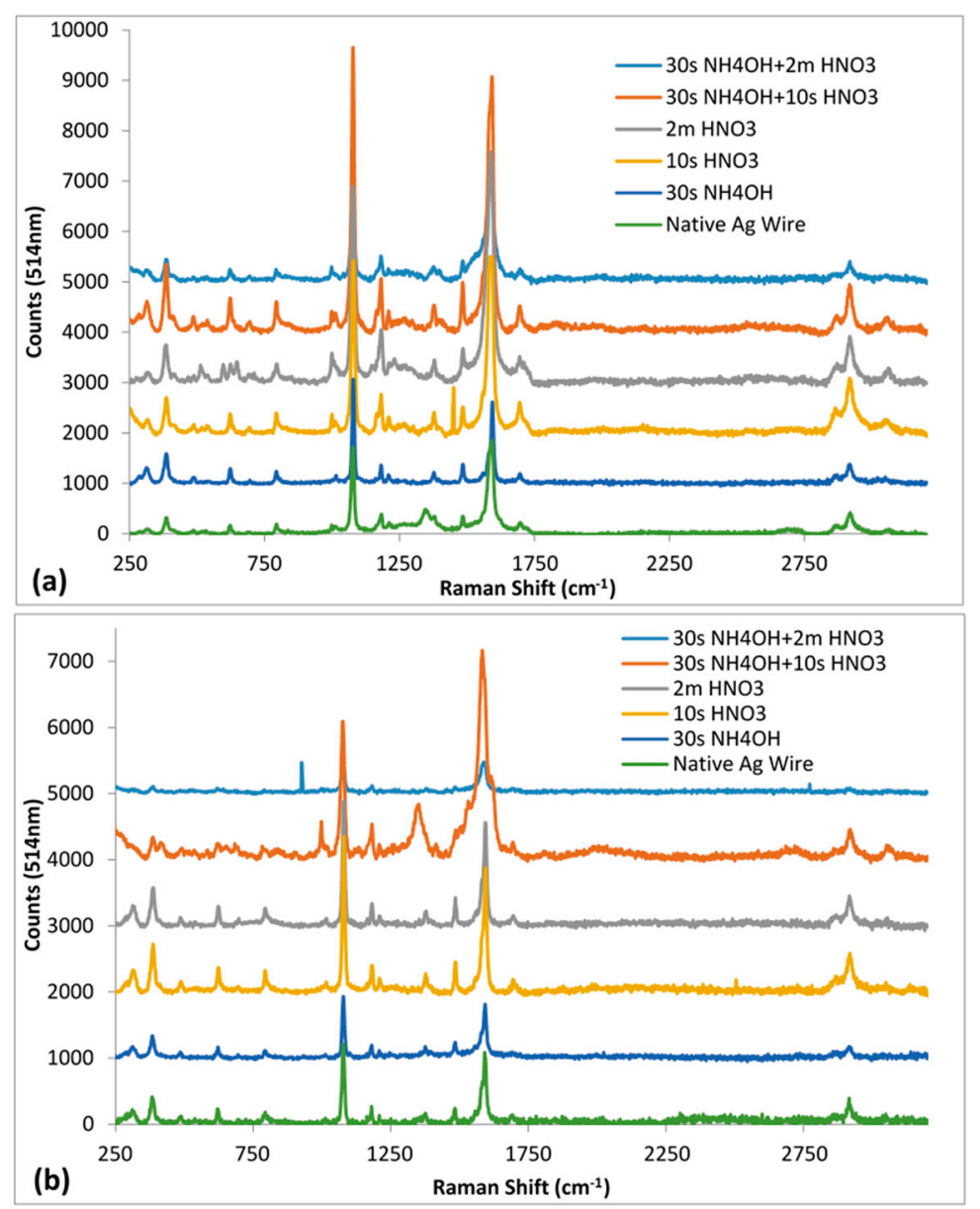

Figure 7. The $514 \mathrm{~nm}$ Raman spectra for the native and chemically treated Ag wires with $1 \mathrm{mM}$ MBT:

(a) non-heated; and (b) heated. Spectra offset for clarity.

On the other hand, there were fewer peaks in the 1064 nm SERS spectrum for MBT $(353,608$, 1063, and $\left.1592 \mathrm{~cm}^{-1}\right)$ compared to the $1064 \mathrm{~nm}$ Raman spectrum for solid MBT $(347,609,781,1085$, $1198,1372,1592,2573,2739,2918$ and $3059 \mathrm{~cm}^{-1}$ ) (Table 3). This can be attributed to the weaker SERS signal due to the longer $1064 \mathrm{~nm}$ laser (inverse relation of SERS signal to the fourth power of the laser wavelength).

The $514 \mathrm{~nm}$ SERS spectra for both non-heated and heated chemical etched silver substrates showed spectra resembling that observed for solid MBT (Figure 7a,b). Two SERS peaks of interest for MBT that are prominently enhanced are $\sim 1076 \mathrm{~cm}^{-1}$ and $\sim 1595 \mathrm{~cm}^{-1}$. The absolute intensities for these two SERS peaks for MBT were compared to determine the SERS efficacy of the different test Ag substrates in this study. The SERS spectral data in conjunction with the interferometry based surface roughness results indicated that the separation between surface roughness features plays an important role in determining the degree of SERS enhancements (Figure 7a,b, Table 4). 
Table 4. SERS enhancements for the different test Ag substrates, in this study: As illustrated by the absolute intensities (AI, counts \pm standard error of mean, $n=4)$ and enhancement factors $\left(\mathrm{EF} \times 10^{5}\right)$ for the $\sim 1076 \mathrm{~cm}^{-1}$ and the $\sim 1595 \mathrm{~cm}^{-1}$ SERS peaks for $1 \mathrm{mM} \mathrm{MBT}$ as a function of chemical etching, with and without heat treatments using $514 \mathrm{~nm}$ laser wavelength.

\begin{tabular}{|c|c|c|c|c|c|c|c|c|}
\hline & \multicolumn{4}{|c|}{$1076 \mathrm{~cm}^{-1}$} & \multicolumn{4}{|c|}{$1595 \mathrm{~cm}^{-1}$} \\
\hline & \multicolumn{2}{|c|}{ Non-Heated } & \multicolumn{2}{|c|}{ Heated } & \multicolumn{2}{|c|}{ Non-Heated } & \multicolumn{2}{|c|}{ Heated } \\
\hline & AI Counts & $\mathrm{EF} \times 10^{5}$ & AI Counts & $\mathrm{EF} \times 10^{5}$ & AI Counts & $\mathrm{EF} \times 10^{5}$ & AI Counts & $\mathrm{EF} \times 10^{5}$ \\
\hline Native Ag Substrate & $1728 \pm 629$ & 3.3 & $1209 \pm 901$ & 2.3 & $1883 \pm 779$ & 5.3 & $1087 \pm 957$ & 3.0 \\
\hline $30 \mathrm{~s} \mathrm{NH}_{4} \mathrm{OH}$ & $2104 \pm 266$ & 4.0 & $933 \pm 414$ & 1.8 & $1630 \pm 126$ & 4.6 & $815 \pm 283$ & 2.3 \\
\hline $10 \mathrm{~s} \mathrm{HNO}_{3}$ & $3506 \pm 446$ & 6.6 & $2352 \pm 330$ & 4.5 & $3656 \pm 584$ & 10.2 & $1876 \pm 357$ & 5.2 \\
\hline $2 \mathrm{~m} \mathrm{HNO}_{3}$ & $1035 \pm 336$ & 2.0 & $1884 \pm 337$ & 3.6 & $4672 \pm 622$ & 13.1 & $1563 \pm 362$ & 4.4 \\
\hline $30 \mathrm{~s} \mathrm{NH}_{4} \mathrm{OH}+10 \mathrm{~s} \mathrm{HNO}_{3}$ & $5825 \pm 849$ & 11.0 & $2093 \pm 549$ & 4.0 & $6027 \pm 989$ & 16.9 & $3166 \pm 964$ & 8.9 \\
\hline $30 \mathrm{~s} \mathrm{NH}_{4} \mathrm{OH}+2 \mathrm{~m} \mathrm{HNO}_{3}$ & $1994 \pm 495$ & 3.8 & $434 \pm 109$ & 0.8 & $2257 \pm 540$ & 6.3 & $476 \pm 92$ & 1.3 \\
\hline
\end{tabular}

The enhancement factor (EF) for the SERS peaks, $\sim 1076 \mathrm{~cm}^{-1}$ and $\sim 1595 \mathrm{~cm}^{-1}$, of MBT was estimated using the standard equation: $\mathrm{EF}=\left(\mathrm{I}_{\mathrm{SERS}} / \mathrm{N}_{\mathrm{SERS}}\right) /\left(\mathrm{I}_{\mathrm{RS}} / \mathrm{N}_{\mathrm{RS}}\right)$, where $\mathrm{I}_{\mathrm{SERS}}$ was the SERS absorption counts (absolute intensity) provided by the number of MBT molecules ( $\mathrm{N}_{\text {SERS }}$ ) estimated to be present within the incident laser light field, while $\mathrm{I}_{\mathrm{RS}}$ was the corresponding absolute intensity provided by the estimated number of MBT molecules $\left(\mathrm{N}_{\mathrm{RS}}\right)$ in the normal Raman spectrum. The EF calculations were modelled with that reported by Chen et al [41]. Assuming that immersion in $1 \mathrm{mM}$ MBT would provide a dense monolayer of MBT on the surface of the Ag SERS substrate, which is estimated to be 4 MBT molecules $/ \mathrm{nm}^{2}$ [41]. With a laser spot size of $12.68 \mu \mathrm{m}$ for the $514 \mathrm{~nm}$ Raman spectrometer with a $20 \times$ objective (0.4 N.A.), the number of MBT molecules interrogated for SERS spectrum were estimated to be $\sim 5.1 \times 10^{8}$. The corresponding number of MBT molecules interrogated for normal Raman spectrum was estimated to be $\sim 2.0 \times 10^{14}$. This estimation was based on the theoretical volume of MBT molecule of about $300 \AA^{3}$ [41], an illuminated area of diameter $12.68 \mu \mathrm{m}$ and a laser penetration depth of about $484 \mu \mathrm{m}$ at $5 \mathrm{~mW}$ laser power. The estimated enhancement factors for MBT on the different test Ag SERS substrates in this study were in the region of $10^{5}$ times (Table 4). Typical SER enhancement estimations fall in the range of $10^{4}$ to $10^{8}$ [38] and hence SERS enhancement factor greater than $10^{5}$ observed here for the non-resonant Raman active molecule, MBT, is comparable to that typically reported in literature.

Among the non-heated $\mathrm{Ag}$ substrates, the $30 \mathrm{~s} \mathrm{NH} \mathrm{N}_{4} \mathrm{OH}+10 \mathrm{~s} \mathrm{HNO}_{3}$ treatment produced the highest SERS enhancement, while that by non-chemical etched native Ag substrate the lowest for the MBT peaks-1076 cm $\mathrm{cm}^{-1}$ and $1595 \mathrm{~cm}^{-1}$ (Figure 7a, Table 4). The surface roughness was lowest for $30 \mathrm{~s} \mathrm{NH}_{4} \mathrm{OH} \mathrm{Ag}$ substrate, but its surface topography was similar to that observed for native $\mathrm{Ag}$ substrate. Similarly, the SERS enhancement for $\mathrm{NH}_{4} \mathrm{OH}$ was comparable to that observed for Native Ag substrate. At the other end, $30 \mathrm{~s} \mathrm{NH}_{4} \mathrm{OH}+2 \mathrm{~m} \mathrm{HNO}_{3} \mathrm{Ag}$ substrate had the roughest surface. However, it showed the lowest SERS enhancement among the four different $\mathrm{HNO}_{3}$ treated samples, which can be attributed to the larger separation between roughness features on their surface. The $10 \mathrm{~s}$ $\mathrm{HNO}_{3}$ and the $30 \mathrm{~s} \mathrm{NH} 4 \mathrm{OH}+10 \mathrm{~s} \mathrm{HNO}_{3} \mathrm{Ag}$ substrates showed a flaky morphology with narrow gaps between the flaky features compared to the $2 \mathrm{~m} \mathrm{HNO}_{3}$ and the $30 \mathrm{~s} \mathrm{NH}_{4} \mathrm{OH}+2 \mathrm{~m} \mathrm{HNO}_{3} \mathrm{Ag}$ substrates. Thus, the highest SERS enhancements observed for both the MBT peaks, $1076 \mathrm{~cm}^{-1}$ and $1595 \mathrm{~cm}^{-1}$, suggests that $30 \mathrm{~s} \mathrm{NH}_{4} \mathrm{OH}+10 \mathrm{~s} \mathrm{HNO}_{3}$ treatment produced $\mathrm{Ag}$ substrates having optimum separation between its surface roughness features.

Heat treatment at $130{ }^{\circ} \mathrm{C}$ for $1 \mathrm{~h}$ caused a decrease in SERS enhancements for each of the test $\mathrm{Ag}$ substrates compared to their respective non-heated counterparts (Figure 7b, Table 4). $30 \mathrm{~s} \mathrm{NH}_{4} \mathrm{OH}+$ $10 \mathrm{~s} \mathrm{HNO}_{3} \mathrm{Ag}$ substrate again had the highest SERS enhancement. However, $30 \mathrm{~s} \mathrm{NH}_{4} \mathrm{OH}+2 \mathrm{~m} \mathrm{HNO}_{3}$ showed the lowest SERS enhancement (Figure 7b, Table 4). The general decrease in SERS enhancements caused by heating, again, in conjunction with the general decrease in roughness parameters $\left(R_{t}, R_{q}\right.$ and $R_{a}$ ) further indicates that the height of the roughness features on the surface of the Ag substrates also plays an important role in the SERS signal intensities. This decreasing effect was maximum 
for $30 \mathrm{~s} \mathrm{NH}_{4} \mathrm{OH}+2 \mathrm{~m} \mathrm{HNO}_{3} \mathrm{Ag}$ substrate, suggesting that the longer $\mathrm{HNO}_{3}$ treatment duration potentially results in relatively fragile surface features susceptible to heat induced reorganization of surface roughness. On the other hand, the anomaly of increased roughness for $30 \mathrm{~s} \mathrm{NH}_{4} \mathrm{OH} \mathrm{Ag}$ substrate caused by heating, in turn, did not translate to increased SERS enhancement. This indicates that there not only exists an optimum spacing between the roughness features, but also an optimum height for realising the maximum SERS enhancement.

\subsection{Quantitation of MBT Using SERs on $30 \mathrm{~s} \mathrm{NH}_{4} \mathrm{OH}+10 \mathrm{~s} \mathrm{HNO}_{3} \mathrm{Ag}$ Substrate}

The non-heated $30 \mathrm{~s} \mathrm{NH}_{4} \mathrm{OH}+10 \mathrm{~s} \mathrm{HNO}_{3} \mathrm{Ag}$ substrate that produced the best SERS enhancement was then carried forward for quantitation of MBT using both $514 \mathrm{~nm}$ and $1064 \mathrm{~nm}$ Raman spectrometers. The absolute intensities for the SERS peaks, $1076 \mathrm{~cm}^{-1}$ and $\sim 1595 \mathrm{~cm}^{-1}$, on both the $514 \mathrm{~nm}$ and $1064 \mathrm{~nm}$ SERS spectra (Figure 8a,c) for MBT as a function of concentration were used for plotting standard curves (Figure 8b,d) for quantitation of MBT. The linearity $\left(R^{2}>0.99\right)$ observed for SERS peak intensities for both $\sim 1076 \mathrm{~cm}^{-1}$ and $\sim 1595 \mathrm{~cm}^{-1}$ on both $514 \mathrm{~nm}$ and $1064 \mathrm{~nm}$ SERS spectra as a function of concentration was remarkable. Linear detection ranges tested, in this study, for quantitation of MBT were $100 \mathrm{nM}$ to $1 \mathrm{mM}$ using $514 \mathrm{~nm}$ Raman and $100 \mu \mathrm{M}$ to $1 \mathrm{M}$ using $1064 \mathrm{~nm}$ Raman. Regarding the limit of detection, the SERS peak intensities for both $\sim 1076 \mathrm{~cm}^{-1}$ and $\sim 1595 \mathrm{~cm}^{-1}$ peaks were above the background noise at concentrations $\geq 1 \mathrm{pM}$ using $514 \mathrm{~nm}$ and $\geq 100 \mu \mathrm{M}$ using $1064 \mathrm{~nm}$ Raman spectroscopy for MBT.

SERS enhancement efficacy is the fundamental property of a SERS substrate and Ag metal as a SERS substrate is known to provide the best SERS enhancement typically in the visible to near-infrared excitation [20,42]. In this study, we showed that chemically roughened solid Ag metal provides SERS enhancement even with the $1064 \mathrm{~nm}$ laser Raman spectrometer. Longer wavelength Raman spectroscopy requires higher laser powers to obtain meaningful Raman/SERS spectra. The higher laser power, in turn, causes heating and destruction of most SERS substrates [42]. The $1064 \mathrm{~nm}$ laser SERS spectra obtained with the chemically etched Ag substrate can be attributed to the ability of the solid Ag metal to dissipate the heat generated by the high power laser. From our experience (unpublished data), metal nanoparticles, nano-patterned polymer substrates coated with metal or metal nanoparticles' coated filter papers all fail to provide SERS spectra due to destruction of the substrate by the high power $1064 \mathrm{~nm}$ laser beam. Thus, the heat dissipation ability of Ag metal can potentially open up the use of longer wavelength Raman spectroscopy for SERS-based detection. Such broadband SERS substrates would be beneficial for a universal lab-on-a-chip device [43].

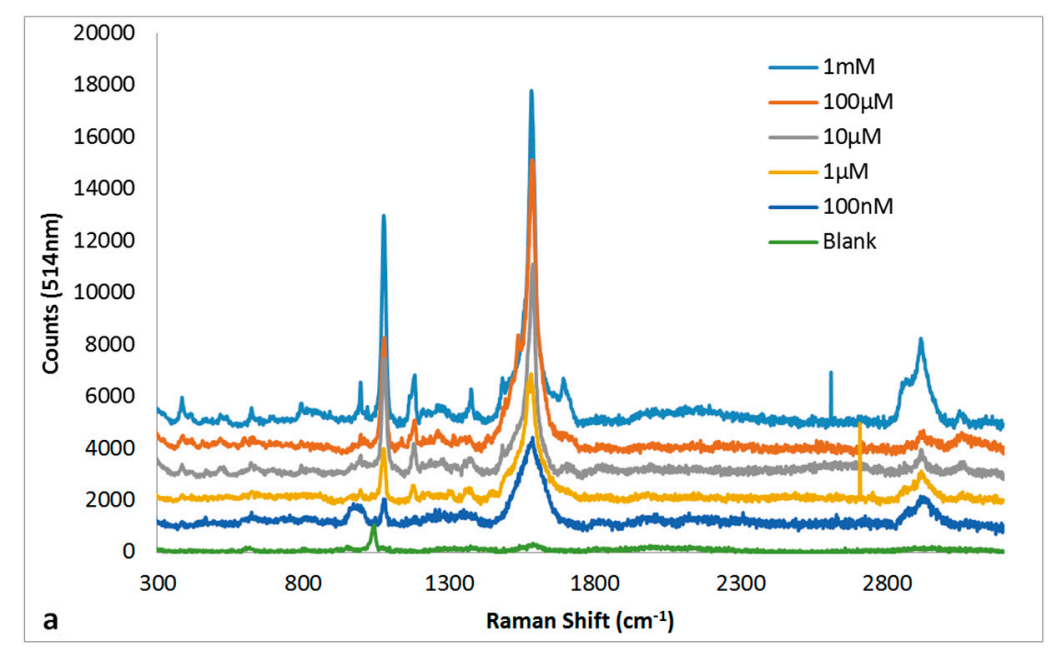

Figure 8. Cont. 


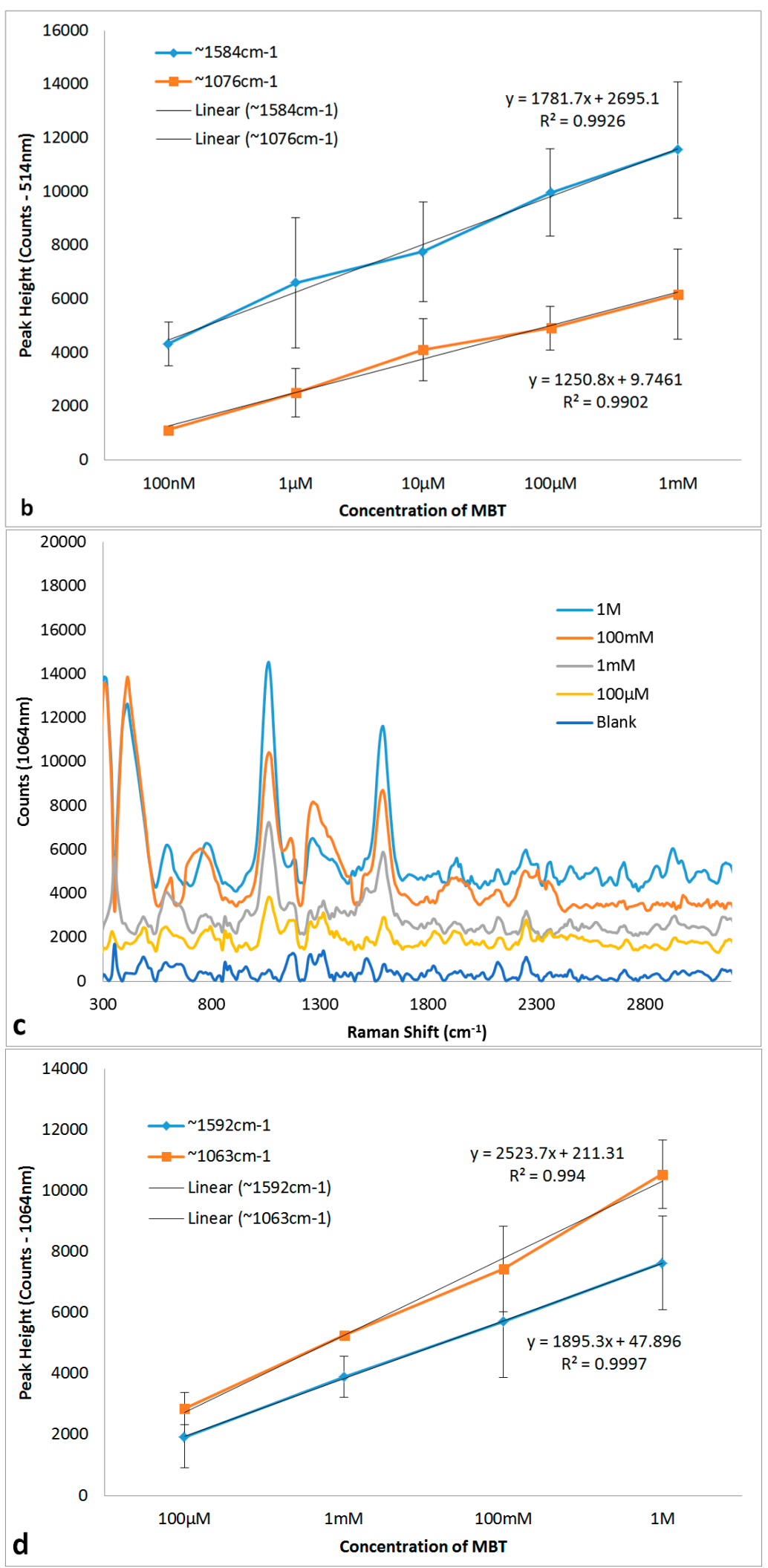

Figure 8. SERS spectra for MBT $(\mathbf{a}, \mathbf{c})$ as a function of concentration and their corresponding standard curves for the peaks $\sim 1076 \mathrm{~cm}^{-1}$ and $\sim 1584 \mathrm{~cm}^{-1}$ (b,d) recorded using $514 \mathrm{~nm}(\mathbf{a}, \mathbf{b})$ and $1064 \mathrm{~nm}$ $(\mathbf{c}, \mathbf{d})$ Raman spectrometers. The SERS spectra (a,c) are offset by $1000 \mathrm{~cm}^{-1}$ for clarity. The peak heights $(\mathbf{b}, \mathbf{d})$ are presented as mean \pm standard error of mean $(n=6)$. 


\section{Conclusions}

In this study, we showed the efficacy of passive chemical etching with $\mathrm{NH}_{4} \mathrm{OH}$ and $/$ or $\mathrm{HNO}_{3}$ on generating roughened surface on solid Ag metal for SERS detection using $514 \mathrm{~nm}$ and $1064 \mathrm{~nm}$ Raman spectrometers. MBT (p-thiocresol), a Raman active molecule, was used to assess SERS efficacy of these substrates. The effect of heating on surface roughness and SERS efficacy of the native and chemical etched $\mathrm{Ag}$ substrates was also investigated. Etching with $35 \% \mathrm{NH}_{4} \mathrm{OH}$ for 30 s resulted in smoothening of the Ag surface, whilst etching for $10 \mathrm{~s}$ or $2 \mathrm{~m}$ with $6 \mathrm{M} \mathrm{HNO}_{3}$ produced a much rougher surface. Synergistic effect of the smoothening by $30 \mathrm{~s} \mathrm{NH} \mathrm{NH}_{4} \mathrm{OH}$ treatment followed by $10 \mathrm{~s}$ or $2 \mathrm{~m}$ etching by $\mathrm{HNO}_{3}$ produced uniformly distributed surface roughness features. Quantitative interferometry results showed microscale roughness (maximum peak to valley distance ranging between 10 and $15 \mu \mathrm{m}$ ) on all test $\mathrm{Ag}$ substrates. The $30 \mathrm{~s} \mathrm{NH} 4 \mathrm{OH}+2 \mathrm{~m} \mathrm{HNO}_{3}$ treatment produced the roughest surface (more peaks and valleys in conjunction with larger peak heights and deeper valleys from the mean linear surface). However, the surface with comparatively lower roughness generated by $30 \mathrm{~s} \mathrm{NH} \mathrm{NH}_{4} \mathrm{OH}+10 \mathrm{~s} \mathrm{HNO}_{3}$ treatment produced the maximum SERS enhancement for the Ag substrate indicating that there is an optimum height of and spacing between the surface roughness features wherein SERS enhancement is maximised. Further proof that optimum spacing and height of the surface roughness features determine the degree of SERS enhancement is observed with heat treatment of the different Ag substrates. Heating caused a restructuring of the surface roughness features resulting in a general decrease not only in the surface roughness, but also in the SERS enhancement for all test $\mathrm{Ag}$ substrates. The $30 \mathrm{~s} \mathrm{NH} \mathrm{NH}_{4} \mathrm{OH}+10 \mathrm{~s} \mathrm{HNO}_{3} \mathrm{Ag}$ substrate that gave the best SERS enhancement was then tested for efficacy in quantifying MBT using $514 \mathrm{~nm}$ and $1064 \mathrm{~nm}$ Raman spectrometers. Standard curves with $\mathrm{R}^{2}>0.99$ and limits of detection of 1 pM and $100 \mu \mathrm{M}$ respectively on $514 \mathrm{~nm}$ and $1064 \mathrm{~nm}$ SERS spectra were obtained using absolute intensities for the typical SERS peaks at $\sim 1076 \mathrm{~cm}^{-1}$ and $\sim 1595 \mathrm{~cm}^{-1}$ of MBT. Our results clearly demonstrate the rapid and the synergistic effect of ammonia and nitric acid treatments in generating a robust broadband SERS substrate on solid Ag metal surface for SERS detection and quantitation. Of particular interest is the ability of solid Ag metal in generating reliable SERS enhancements through dissipation of heat generated by high power lasers (e.g., $1064 \mathrm{~nm}$ ) used in longer wavelength Raman spectroscopy.

Acknowledgments: This work was financially supported by Home Office UK through the SBRI programme of Innovate UK, Grant No. SBRI_HO_202_007 (HOS/14/003). S. Wijesuriya acknowledges the fellowship for her Ph.D. from Brunel Institute for Bioengineering, Brunel University. We also acknowledge the support from Brunel University-RCUK fund for open access publishing.

Author Contributions: Krishna Burugapalli, Shavini Wijesuriya, Ruth Mackay and Wamadeva Balachandran conceived and designed the experiments; Shavini Wijesuriya and Godwin Ajaezi performed the experiments; Shavini Wijesuriya, Krishna Burugapalli and Godwin Ajaezi analysed the data; Shavini Wijesuriya and Krishna Burugapalli wrote the paper; and Ruth Mackay and Wamadeva Balachandran provided valuable insights in the experiments and manuscript writing.

Conflicts of Interest: The authors declare no conflict of interest.

\section{References}

1. Betz, J.F.; Yu, W.W.; Cheng, Y.; White, I.M.; Rubloff, G.W. Simple SERS substrates: Powerful, portable, and full of potential. Phys. Chem. Chem. Phys. 2014, 16, 2224-2239. [CrossRef] [PubMed]

2. Nuntawong, N.; Eiamchai, P.; Wong-ek, B.; Horprathum, M.; Limwichean, K.; Patthanasettakul, V.; Chindaudom, P. Shelf time effect on SERS effectiveness of silver nanorod prepared by OAD technique. Vacuum 2013, 88, 23-27. [CrossRef]

3. Lin, X.-M.; Cui, Y.; Xu, Y.-H.; Ren, B.; Tian, Z.-Q. Surface-enhanced Raman spectroscopy: Substrate-related issues. Anal. Bioanal. Chem. 2009, 394, 1729-1745. [CrossRef] [PubMed]

4. Song, C.; Abell, J.L.; He, Y.; Hunyadi Murph, S.; Cui, Y.; Zhao, Y. Gold-modified silver nanorod arrays: Growth dynamics and improved SERS properties. J. Mater. Chem. 2012, 22, 1150-1159. [CrossRef] 
5. Wu, W.; Liu, L.; Dai, Z.; Liu, J.; Yang, S.; Zhou, L.; Xiao, X.; Jiang, C.; Roy, V.A. Low-Cost, Disposable, Flexible and Highly Reproducible Screen Printed SERS Substrates for the Detection of Various Chemicals. Sci. Rep. 2015, 5, 10208. [CrossRef] [PubMed]

6. Le Ru, E.C.; Etchegoin, P.G. Chapter 1-A quick overview of surface-enhanced Raman spectroscopy. In Principles of Surface-Enhanced Raman Spectroscopy; Elsevier: Amsterdam, The Netherlands, 2009; pp. 1-27.

7. Kneipp, K.; Wang, Y.; Kneipp, H.; Perelman, L.T.; Itzkan, I.; Dasari, R.R.; Feld, M.S. Single Molecule Detection Using Surface-Enhanced Raman Scattering (SERS). Physical Rev. Lett. 1997, 78, 1667-1670. [CrossRef]

8. Nie, S.; Emory, S.R. Probing Single Molecules and Single Nanoparticles by Surface-Enhanced Raman Scattering. Science 1997, 275, 1102-1106. [CrossRef] [PubMed]

9. Alvarez-Puebla, R.A.; Liz-Marzán, L.M. SERS-Based Diagnosis and Biodetection. Small 2010, 6, 604-610. [CrossRef] [PubMed]

10. Chen, L.; Choo, J. Recent advances in surface-enhanced Raman scattering detection technology for microfluidic chips. Electrophoresis 2008, 29, 1815-1828. [CrossRef] [PubMed]

11. Fleischmann, M.; Hendra, P.J.; McQuillan, A.J. Raman spectra of pyridine adsorbed at a silver electrode. Chem. Phys. Lett. 1974, 26, 163. [CrossRef]

12. Wet Chemical Etching. 2013. Available online: http://www.microchemicals.com/technical_information/ wet_etching.pdf (accessed on 2 June 2016).

13. Tarn, W.H.; Walker, P. CRC Handbook of Metal. Etchants; CRC Press: London, UK, 1990.

14. Miller, S.K.; Baiker, A.; Meier, M.; Wokaun, A. Surface-enhanced Raman scattering and the preparation of copper substrates for catalytic studies. J. Chem. Soc. Faraday Trans. 1 1984, 80, 1305-1312. [CrossRef]

15. Xue, G.; Dong, J.; Zhang, M. Surface-Enhanced Raman Scattering (SERS) and Surface-Enhanced Resonance Raman Scattering (SERRS) on HNO3-Roughened Copper Foil. Appl. Spectrosc. 1991, 45, 756-759. [CrossRef]

16. Xue, G.; Dong, J. Stable silver substrate prepared by the nitric acid etching method for a surface-enhanced Raman scattering study. Anal. Chem. 1991, 63, 2393-2397. [CrossRef]

17. Ruperez, A.; Laserna, J.J. Surface-enhanced Raman sensor. Analusis 1995, 23, 91-93.

18. Ruperez, A.; Laserna, J.J. Surface-enhanced Raman spectrometry of triamterene on a silver substrate prepared by the nitric acid etching method. Talanta 1997, 44, 213-220. [CrossRef]

19. Pérez, R.; Rupérez, A.; Rodriguez-Castellón, E.; Laserna, J.J. Study of experimental parameters for improved adsorbate detectability in SERS using etched silver substrates. Surf. Interface Anal. 2000, 30, 592-596. [CrossRef]

20. Sharma, B.; Frontiera, R.R.; Henry, A.-I.; Ringe, E.; Van Duyne, R.P. SERS: Materials, applications, and the future. Mater. Today 2012, 15, 16-25. [CrossRef]

21. Stiles, P.L.; Dieringer, J.A.; Shah, N.C.; Van Duyne, R.P. Surface-Enhanced Raman Spectroscopy. Annu. Rev. Anal. Chem. 2008, 1, 601-626. [CrossRef] [PubMed]

22. Moskovits, M. Surface-enhanced Raman spectroscopy: A brief retrospective. J. Raman Spectrosc. 2005, 36, 485. [CrossRef]

23. Otto, A.; Mrozek, I.; Grabhorn, H.; Akemann, W. Surface-enhanced Raman scattering. J. Phys. Condens. Matter 1992, 4, 1143-1212. [CrossRef]

24. Baker, G.A.; Moore, D.S. Progress in plasmonic engineering of surface-enhanced Raman-scattering substrates toward ultra-trace analysis. Anal. Bioanal. Chem. 2005, 382, 1751. [CrossRef] [PubMed]

25. Surface Texture Parameters, Zygo, Electronic Resource No. OMP-0514C 04/2013. Available online: http:/ / www.zygo.com/library/papers/SurfText.pdf (accessed on 2 June 2016).

26. Wang, N.; Burugapalli, K.; Song, W.; Halls, J.; Moussy, F.; Ray, A.; Zheng, Y. Electrospun fibro-porous polyurethane coatings for implantable glucose biosensors. Biomaterials 2013, 34, 888-901. [CrossRef] [PubMed]

27. Wang, N.; Burugapalli, K.; Song, W.; Halls, J.; Moussy, F.; Zheng, Y.; Ma, Y.; Wu, Z.; Li, K. Tailored fibro-porous structure of electrospun polyurethane membranes, their size-dependent properties and trans-membrane glucose diffusion. J. Memb. Sci. 2013, 427, 207-217. [CrossRef] [PubMed]

28. Wang, N.; Burugapalli, K.; Wijesuriya, S.; Far, M.Y.; Song, W.; Moussy, F.; Zheng, Y.; Ma, Y.; Wu, Z.; Li, K. Electrospun polyurethane-core and gelatin-shell coaxial fibre coatings for miniature implantable biosensors. Biofabrication 2014, 6, 015002. [CrossRef] [PubMed]

29. Muniz-Miranda, M.; Gellini, C.; Innocenti, M. SERS Spectroscopy and Microscopy. In Raman Spectroscopy for Nanomaterials Characterization; Challa, S.S.R.K., Ed.; Springer: Heidelberg/Berlin, Germany, 2012; pp. 553-586. 
30. Muniz-Miranda, M.; Gellini, C.; Salvi, P.R.; Innocenti, M.; Pagliai, M.; Schettino, V. Fabrication of nanostructured silver substrates for surface-enhanced Raman spectroscopy. J. Nanopart. Res. 2011, 13, 5863-5871. [CrossRef]

31. Goh, M.S.; Lee, Y.H.; Pedireddy, S.; Phang, I.Y.; Tjiu, W.W.; Tan, J.M.R. A Chemical Route to Increase Hot Spots on Silver Nanowires for Surface-Enhanced Raman Spectroscopy Application. Langmuir 2012, 28, 14441-14449. [CrossRef] [PubMed]

32. Lowe, H.F.; Spindloe, C. White light interferometric profilometry of surface structured glass for high power laser microtargets; Chapter 7 in Laser Science and Development, Target Fabrication. In Central Laser Facility, Annual Report (RAL-TR-2007-025); Rutherford Appleton Laboratory: Didcot, UK, 2006/2007; pp. 249-252.

33. Rolinski, E.; Konieczny, A.; Sharp, G. Nature of Surface Changes in Stamping Tools of Gray and Ductile Cast Iron During Gas and Plasma Nitrocarburizing. J. Mater. Eng. Perform. 2009, 18, 1052-1059. [CrossRef]

34. Lai, Y.; Wang, J.; He, T.; Sun, S. Improved Surface Enhanced Raman Scattering for Nanostructured Silver on Porous Silicon for Ultrasensitive Determination of 2,4,6-Trinitrotoluene. Anal. Lett. 2014, 47, 833-842. [CrossRef]

35. Jeanmaire, D.L.; Van Duyne, R.P. Surface raman spectroelectrochemistry: Part I. Heterocyclic, aromatic, and aliphatic amines adsorbed on the anodized silver electrode. J. Electroanal. Chem. Interfacial Electrochem. 1977, 84, 1-20. [CrossRef]

36. Lu, Y.; Xue, G. Study of surface catalytic photochemical reaction by using conventional and Fourier transform surface enhanced Raman scattering. Appl. Surf. Sci. 1998, 125, 157-162. [CrossRef]

37. Jiajia, M.; Jiafang, L.; Wuxia, L.; Qiang, L.; Changzhi, G. Hollow metallic pyramid plasmonic structures fabricated by direct laser writing and electron beam evaporation. Microelectr. Eng. 2013, 110, 307-310.

38. Valley, N.; Greeneltch, N.; Van Duyne, R.P.; Schatz, G.C. A Look at the Origin and Magnitude of the Chemical Contribution to the Enhancement Mechanism of Surface-Enhanced Raman Spectroscopy (SERS): Theory and Experiment. J. Phys. Chem. Lett. 2013, 4, 2599-2604. [CrossRef]

39. Li, H.; Hanson, C.; Fuchs, J.A.; Woodward, C.; Thomas, G.J. Determination of the pKa values of active-center cysteines, cysteines-32 and -35, in Escherichia coli thioredoxin by Raman spectroscopy. Biochemistry 1993, 32, 5800-5808. [CrossRef] [PubMed]

40. Hommel, E.L.; Allen, H.C. The air-liquid interface of benzene, toluene, m-xylene, and mesitylene: A sum frequency, Raman, and infrared spectroscopic study. Analyst 2003, 128, 750-755. [CrossRef] [PubMed]

41. Chen, J.; Yang, W.; Dick, K.; Deppert, K.; Xu, H.Q.; Samuelson, L.; Xu, H. Tip-enhanced Raman scattering of p-thiocresol molecules on individual gold nanoparticles. Appl. Phys. Lett. 2008, 92, 093110. [CrossRef]

42. Sharma, B.; Fernanda Cardinal, M.; Kleinman, S.L.; Greeneltch, N.G.; Frontiera, R.R.; Blaber, M.G.; Schatz, G.C.; Van Duyne, R.P. High-performance SERS substrates: Advances and challenges. MRS Bull. 2013, 38, 615-624. [CrossRef]

43. Zhang, N.; Liu, K.; Liu, Z.; Song, H.; Zeng, X.; Ji, D.; Cheney, A.; Jiang, S.; Gan, Q. Ultrabroadband Metasurface for Efficient Light Trapping and Localization: A Universal Surface-Enhanced Raman Spectroscopy Substrate for "All" Excitation Wavelengths. Adv. Mater. Interfaces 2015, 2, 1500142. [CrossRef]

(c) 2016 by the authors; licensee MDPI, Basel, Switzerland. This article is an open access article distributed under the terms and conditions of the Creative Commons Attribution (CC-BY) license (http://creativecommons.org/licenses/by/4.0/). 